\title{
Usando o GeoGebra para o ensino de sólidos de revolução
}

\author{
Using GeoGebra for teaching revolution solids
}

\author{
Lucas Rodrigues Pereira, Mario Guimarães Gomes, Nicson Nongelle Gomes \\ Pinheiro, Jaqueline Maria da Silva, Deborah Faragó Jardim e Alexandre Faissal Brito \\ llucasrp@gmail.com; mario.gomes@ufvjm.edu.br; nicsongomes@hotmail.com; jaqueline.silva@ufvjm.edu.br; \\ deborah.farago@ufvjm.edu.br; alexandre.faissal@ufvjm.edu.br \\ Universidade Federal dos Vales do Jequitinhonha e Mucuri, SP, Brasil
}

\section{Resumo}

Este estudo foi desenvolvido baseado nos princípios da Engenharia Didática visando estudar e discutir as contribuições que o uso do software GeoGebra pode oferecer para a compreensão de conceitos matemáticos frequentemente usados para o cálculo de áreas e volumes de sólidos de revolução. Norteando-se pelas quatro etapas propostas pela metodologia de pesquisa, foi realizado um levantamento inicial com intuito de verificar as condições sociais e acadêmicas dos estudantes, bem como o nível de conhecimento sobre os temas trabalhados. Logo após, foi aplicada uma intervenção didática usando o GeoGebra a um grupo de estudantes visando propiciá-los conhecimento suficiente para trabalhar com a matemática dinâmica interativa de modo interligado aos conceitos empíricos e formais de Geometria Espacial, aperfeiçoando sua visão tridimensional e preparando-os para a prática docente de tal conteúdo. Após análises e discussões sobre os resultados obtidos, constatou-se notável progresso dos estudantes no que se refere ao entendimento dos conceitos fundamentais dos tópicos trabalhados.

Palavras-chave: GeoGebra, Engenharia Didática, Ensino, Área, Volume, Sólidos de Revolução

\section{Abstract}

This research was developed based on the principles of the Didactic Engineering, to study and discuss the contributions that the use of the GeoGebra software may offer to understanding of mathematics concepts often used to evaluate areas and volumes of revolution solids. Was applied a didactic intervention using GeoGebra to a group of students to propitiate them knowledge enough to work with a the interactive dynamic geometry interconnecting it to empirical and formal concepts of Spatial Geometry, improving their dimensional view and preparing them for teaching Geometry. After analysis and discussions about the obtained results, were noticed a remarkable progress from the students related to the understanding of the fundamental topics of the Geometry concepts proposed in this work.

Keywords: GeoGebra, Didactic Engineering, Teaching, Area, Volume, Revolution Solids. 


\section{Introdução}

A Geometria enquanto ciência sempre esteve conectada ao modo como o ser humano vê o mundo. Desde a época de Euclides houve grande interesse por parte dos filósofos matemáticos nas formas geométricas e na maneira axiomática e perfeccionista que a matemática formal o caracterizava. Nessa lista de pensadores, segundo Boyer (1996) [6], podem ser incluídos Arquimedes de Siracusa, Apolônio de Perga, Pitágoras, dentre outros. Contudo, após o surgimento do computador e, com ele, a existência de ciberespaços que permitem a experiência de mundos idealizados, nossos principais limites conceituais e expectativas foram superados, exigindo-nos reconfigurar a fronteira que separa o possível do impossível. Neste contexto, podemos observar em Santaella (2003) [20] que as novas tecnologias estão mudando todas as esferas da sociedade, tais como: econômica, política, social e educacional

Por consequência, Pereira (2017) [17] afirma que nesse novo período de virtualização dos espaços de convivência e de interação social, trazida com o mundo digital, a observação, a descrição e a construção das formas matemáticas não são mais atividades essencialmente cognitivas como antes. Além disso, Machado (2010) [14], afirma que a possibilidade de estruturar uma cibercultura propicia a ampliação das funções cognitivas humanas, tais como a memória e o raciocínio da inteligência artificial. Desta forma, a assimilação das pessoas sobre o que era observado na natureza ou nos objetos criados pelo homem pode ser reproduzida em espaços digitalmente simulados através de programas computacionais para manipulação geométrica interativa.

Neste sentido, a escola como um espaço privilegiado de discussão, produção e estruturação do conhecimento, deve oferecer aos profissionais da educação e estudantes meios para se integrarem neste contexto de novos recursos computacionais, visando estimular e fortalecer o processo de ensino e aprendizagem. E assim, através do seu uso, permitir que o estudante crie uma relação entre as formas tridimensionais do mundo real e suas possíveis representações matemáticas, explorando sua capacidade de abstração e formalização das ideias.

Porém, é evidente que não basta apenas investir em recursos tecnológicos e em programas de inclusão digital, pois a sua implementação por si só não torna efetivo o uso dos recursos computacionais no processo de ensino aprendizagem. No entanto, as discussões que envolvem o uso dos recursos computacionais no âmbito escolar não são recentes. Diversos pesquisadores discutem as potencialidades e limitações que o seu uso ocasionam no processo de ensino e aprendizagem. Segundo Moran (2004) [15], dentre as dificuldades encontradas ao trabalhar com os recursos computacionais nas aulas de matemática, destaca-se a ineficácia apresentada pelos professores no domínio das tecnologias. Além disso, as aulas ditas tradicionais já não são tão atrativas aos estudantes que a cada dia estão mais tendenciados ao uso das novas tecnologias em seu dia-a-dia.

Buscando reverter a situação que se encontra Educação Básica no Brasil, o Governo Federal tem fomentado vários projetos na área de informática, visando preparar todo corpo docente e discente frente a esse avanço dos recursos tecnológicos, como o Programa Nacional de Formação Continuada em Tecnologia Educacional (PROINFO) ${ }^{1}$, que é voltado para o uso didático-pedagógico dos recursos computacionais no ambiente escolar, no qual são distribuídos equipamentos e recursos multimídia como ferramentas de ensino e aprendizagem.

Surgindo como expoente nesse contexto de tecnologias educacionais, o software de matemática dinâmica GeoGebra $^{2}$ permite, além de muitas outras funcionalidades, trabalhar conceitos da Geometria Euclidiana Espacial em um ambiente virtualizado de caracterização tridimensional, proporcionando ao estudante uma melhor compreensão e interpretação dos conceitos matemáticos estudados. Como por exemplo, Dantas e Mathias (2017) propõem em [10] o uso do GeoGebra para estudo de volumes de forma geométricas sem a introdução de conceitos básicos de Cálculo Diferencial e Integral.

No entanto, Rosa (2013) [19], afirma que é importante observar que é necessário mais que um simples domínio instrumental. O uso dos recursos computacionais requer também o conhecimento de suas ferramentas e suas potencialidades para que possa ser planejado o método de aplicação. É necessário refletir sobre a prática docente e adequar aos novos padrões vigentes, onde o uso de novas tecnologias na educação, apesar de consistirem em um diferencial positivo no processo de ensino e aprendizagem, devem ser usadas com responsabilidade.

Sendo assim, após serem consideradas as reflexões referentes ao uso dos recursos computacionais na educação, este trabalho apresenta um estudo que mostra algumas das potencialidades do software GeoGebra conciliadas às ideias teórico-matemáticas relacionadas ao estudo de áreas e volumes de sólidos de revolução, com o auxílio do Cálculo Diferencial e Integral. Além disso, visa-se a melhoria da práxis pedagógica, possibilitando ao futuro profissional do ensino de matemática a prática do papel de multiplicador do conhecimento, de modo a estimular os estudantes a aceitarem a tecnologia como ferramenta de apoio para o ensino de Geometria e Cálculo Diferencial e

\footnotetext{
${ }^{1}$ Os dados sobre o programa estão disponíveis em: <http://www.portal.mec.gov.br/proinfo/proinfo>

${ }^{2}$ Concebido em 2001 por Markus Hohenwarter, o GeoGebra é um dos mais populares softwares que permitem trabalhar com matemática dinâmica e pode ser obtido em: <http://www.geogebra.org>.
} 
Integral. Neste último caso, um experimento que antecede o trabalho aqui proposto, pode ser encontrado em [13, 21]. Na seção a seguir será realizado um aprofundamento teórico, detalhando as principais características da metodologia de pesquisa utilizada neste trabalho, a Engenharia Didática.

\section{A engenharia didática}

Pesquisas científicas voltadas para o ensino têm se desenvolvido aportadas em diversos tipos de metodologias de pesquisa, nas quais são utilizadas abordagens qualitativas e quantitativas para análise dos dados. Assim, por frequentemente envolver muitos fatores subjetivos, há uma dificuldade dos pesquisadores na escolha e utilização de uma metodologia de pesquisa, de investigação que permita alcançar e discutir resultados relacionados à pesquisas e estudos desenvolvidos em Educação Matemática, pautados em procedimentos didáticos sólidos, como se observa em [8]. Considerando esse contexto, no presente trabalho optou-se por adotar como metodologia de pesquisa a Engenharia Didática.

Inicialmente, o Instituto de Investigação do Ensino de Matemática (IREM) localizado na França, discutia assuntos relacionados à formação de professores de matemática e à produção de materiais didáticos para serem utilizados em sala de aula, tais como jogos, brinquedos, atividades escritas e experimentais. Almouloud e Coutinho (2008) [1] ressaltam que as pesquisas em Didática Matemática da escola francesa são em sua maioria do tipo experimental, onde o pesquisador submete o fenômeno à experimentação e a uma intervenção, que é sistematicamente organizada através dos dados coletados inicialmente.

A partir das discussões oriundas desta temática surgiu a Engenharia Didática, organizada pela pesquisadora francesa Artigue (1996) [5], que a define como uma forma de trabalho didático semelhante ao trabalho do engenheiro que, para realizar um projeto, se fundamenta em conhecimentos científicos de sua área, submete-se ao a um método científico e, em seu desenvolvimento, aceita trabalhar com objetos mais complexos que os objetos de pesquisa [7]. Diversos trabalhos abordam o tema dessa didática, conhecida como Didática Francesa, e em muitos casos adaptados à realidade brasileira, como se observa em [2] e [16].

Um projeto construído nos moldes da Engenharia Didática enquanto metodologia de pesquisa deve conter, segundo Almouloud e Coutinho (2008) [1] quatro etapas a saber: as análises prévias; a construção e a análise $a$ priori; a experimentação; análise a posteriori e validação. Este trabalho apresenta a mesma estrutura sugerida por Almouloud e Coutinho (2008).

\subsection{As etapas da Engenharia Didática}

\subsubsection{Análises Prévias}

Segundo Pereira (2017) [17], esta é a fase na qual o pesquisador realiza as análises preliminares, ou seja, o processo de investigação, de forma que através dos dados observados, seja possível proceder a identificação das variáveis didáticas que serão utilizadas nas fases posteriores.

Desta forma, inicialmente investigou-se os principais motivos que conduzem os estudantes a apresentar dificuldade de aprendizagem em Geometria Espacial. Verificou-se que as principais dificuldades enfrentadas pelos estudantes estão relacionadas:

- a defasagem conceitual referente aos conteúdos de Geometria Plana;

- ao ensino vinculado a fórmulas, onde os estudantes em sua maioria não conseguem relacionar conceitos;

- ao reconhecimento de figuras geométricas planas e tridimensionais;

- a Geometria ser trabalhada separadamente dos outros conteúdos da Matemática;

Após realizada a coleta de dados e análises preliminares, dar-se-á prosseguimento a próxima etapa.

\subsubsection{Construção e Análise a Priori}

Nesta fase, segundo Artigue (1996) [5] o pesquisador deve investigar dois tipos de variáveis: as variáveis macrodidáticas, relacionadas a organização geral da pesquisa e as variáveis microdidáticas, relativas a organização local da pesquisa. 
Para Almouloud e Coutinho (2008) [1], no processo de análise a priori o pesquisador deve: descrever as escolhas das variáveis; verificar a importância da situação do público pesquisado; prever os comportamentos que podem surgir no processo de pesquisa e com as análises feitas, poder controlar o seu sentido.

Desta forma, na análise a priori pode-se definir as seguintes situações:

- Foi detalhadamente planejado e elaborado um questionário com intuito de verificar as condições sociais e acadêmicas dos estudantes participantes da pesquisa. Os dados levantados pelas respostas obtidas nos questionários serviram como base para o planejamento das intervenções e análise dos resultados.

- Definiu-se o GeoGebra como ferramenta principal desta pesquisa. Além disso, foi implementado um minicurso sobre o GeoGebra e seus principais recursos com objetivo de preparar os estudantes para as intervenções futuras.

- Elaborou-se um questionário a priori com objetivo de levantar as principais defasagens conceituais dos estudantes referentes aos temas trabalhados.

- Foram detalhadamente planejadas e elaboradas todas as intervenções didáticas a serem aplicadas durante a etapa da experimentação.

- Elaborou-se um questionário a posteriori contendo questões pertinentes ao tema trabalhado, com intuito de verificar a evolução dos estudantes mediante a um comparativo com o questionário a priori.

- Foi elaborado um questionário de satisfação onde o estudante avaliou qualitativamente os conteúdos trabalhados, a relevância acadêmica desta pesquisa, a postura da equipe de trabalho, entre outras questões subjetivas.

Com base nas discussões e levantamentos iniciais, formulou-se as hipóteses de trabalho a serem confrontadas nas etapa de validação. São elas:

1. A mediação condicionada pela abordagem dinâmica e interativa do GeoGebra promove a visualização e a compreensão geométrica.

2. O uso do Cálculo Integral e Diferencial no cálculo de área e volume de sólidos de revolução contribui com a elucidação das dificuldades apresentadas anteriormente.

3. A atenuação da dificuldade de entendimento das propriedades matemáticas de caráter geométrico com base na visualização.

4. A interdisciplinaridade aplicada ao cálculo de área e volume de sólidos de revolução beneficia o processo de formalização de conceitos.

\subsubsection{Experimentação}

A terceira fase equivale, na concepção da engenharia, a execução da pesquisa, ou seja, é neste momento que o pesquisador, através dos dados obtidos na etapa anterior, põe em prática todo o planejamento.

\subsubsection{Análise a Posteriori e Validação}

Na quarta etapa é feita a validação onde é realizado o confrontamento da análise a priori e análise a posteriori, com o objetivo de validar e contrapor as hipóteses iniciais da pesquisa. É possível encontrar uma descrição mais detalhada das quatro etapas acima citadas em [3].

\subsection{Alguns Conceitos Matemáticos}

Para facilitar a compreensão dos assuntos que serão apresentados neste estudo, apresenta-se a seguir uma breve fundamentação teórica acerca de algumas definições matemáticas que nortearam o trabalho. Para isso, foram tomadas como base as definições apresentadas em Dolce e Pompeu (2001) [11] e Stewart (2006) [22]. É necessário ressaltar que quando não mencionado, deve sempre ser considerado o espaço tridimensional nas definições que seguem: 
- Definição de Superfície de Revolução: Superfície de revolução é a rotação de uma curva em torno de um eixo fixo específico.

- Definição de Sólido de Revolução: Sólido de revolução é o sólido obtido pela rotação de uma região em torno de um eixo fixo específico.

- Definição de Superfície Cilíndrica de Revolução: Superfície cilíndrica de rotação (ou revolução) é uma superfície gerada pela rotação (ou revolução) de uma reta paralela a um eixo fixo específico em torno do mesmo.

- Superfície Cônica de Revolução: Superfície cônica de revolução é a superfície gerada pela rotação (ou revolução) de uma reta em torno de um eixo fixo, sendo que a reta é oblíqua ao eixo e tem apenas um único ponto de intersecção com o mesmo, denotado vértice.

- Superfície Esférica: Superfície esférica é o conjunto formado por todos os pontos do espaço cuja distância ao ponto fixo $O$ é igual a uma medida fixa denotada por raio.

- Cilindro de Revolução: Cilindro de revolução é o sólido obtido através da revolução (ou rotação) da região delimitada por um eixo fixo específico e uma reta paralela a este em torno do eixo fixo dado.

- Cone de Revolução: Cone de revolução é o sólido obtido através da revolução (ou rotação) da região delimitada por um eixo fixo específico e uma reta oblíqua a este em torno do eixo fixo dado.

- Esfera: Esfera é o conjunto formado por todos os pontos do espaço cuja distância ao ponto $O$ é menor ou igual a uma medida fixa denotada por raio, o ponto $O$ é chamado de centro.

- Área: Área é a medida da quantidade de espaço bidimensional de uma estrutura.

- Volume: Volume é a medida da quantidade de espaço tridimensional de uma estrutura.

É importante ressaltar que os conceitos matemáticos aqui apresentados e definidos devem ter sua aceitabilidade restringida às necessidades específicas das atividades do trabalho proposto, uma vez que sua contundência técnica foi limitada com o objetivo de facilitar seu entendimento.

\section{Desenvolvimento}

Visando avaliar as condições econômicas, sociais e acadêmicas dos estudantes submetidos à intervenção didática, o desenvolvimento da oficina se deu inicialmente com a elaboração e a aplicação de um questionário socioeconômico e acadêmico. Ao discutir os resultados obtidos pelo questionário, foi possível observar que todos os estudantes tinham acesso regular ao computador, além de conhecimento necessário para seu manuseio em atividades acadêmicas básicas. Além disso, o questionário também mostrou que, em sua totalidade, os estudantes utilizavam frequentemente algum software matemático, sendo que cerca de 85,7\% já haviam utilizado o GeoGebra em alguma outra atividade acadêmica. No entanto nenhum dos estudantes havia feito um curso específico, que explorasse as ferramentas dinâmicas do software, ou seja, os estudantes haviam apenas desenvolvido atividades corriqueiras com a ferramenta.

Assim, identificou-se a necessidade de um minicurso introdutório ao software, cuja finalidade foi promover a familiarização dos estudantes usuários com as ferramentas necessárias para desenvolvimento das atividades da intervenção didática. Ademais, quando também observados os dados do questionário de avaliação diagnóstica $a$ priori, foi observada e discutida a necessidade de uma adequação no cronograma do planejamento e da execução das atividades, pois claramente os estudantes apresentavam dificuldades conceituais em relação aos tópicos a serem abordados e possuíam deficiência no processo de abstração e formalização dos conceitos matemáticos relacionados aos sólidos e às superfícies de revolução.

Neste contexto, com base na Engenharia Didática, planejou-se a intervenção didática com o software para ser desenvolvida em três etapas, sendo elas: um minicurso introdutório ao programa; uma aula prática, no ambiente de matemática dinâmica do software GeoGebra e, por fim, uma aula teórica para formalização conceitual, com o uso do cálculo diferencial e integral, sendo pertinente ressaltar que o minicurso introdutório foi previamente planejado para que, caso necessário, fosse finalizado com as devidas adequações, conforme planejamento embasado nos dados obtidos através da análise preliminar feita a partir do questionário socioeconômico e acadêmico. 


\subsection{O minicurso introdutório}

Seguindo rigorosamente o planejamento, no primeiro dia de intervenção, o minicurso de introdução aos comandos do GeoGebra foi iniciado com informações sobre o site $\mathbf{O}$ GeoGebra ${ }^{3}$, enfatizando a qualidade e a quantidade de material informativo disponível gratuitamente no portal. Em seguida, os estudantes foram convidados a acessarem o site mencionado e a assistirem o vídeo sobre o software intitulado "Interface e construções iniciais", com duração de 12 minutos apresentando o software e alguns de seus principais comandos básicos.

Após a exibição do vídeo foram trabalhadas algumas atividades complementares com os estudantes, tais como criação do controle deslizante; a abertura da janela de visualização $3 D$, a criação de animações, dentre outras. Em seguida, foram destinados 35 minutos para algumas atividades individuais, nas quais os estudantes pudessem utilizar e explorar os comandos ensinados, com objetivo de familiarizá-los a interface e método de trabalho com o programa que seriam utilizados na aula de construção das superfícies e sólidos de revolução.

Ao final do minicurso introdutório, as atividades foram discutidas e corrigidas com os estudantes. Além disso, uma atividade extraclasse, foi proposta com roteiro passo a passo, propondo uma construção mais complexa, cuja correção ficou programada para o segundo dia de intervenção didática.

\subsection{A aula prática}

No início desta etapa a atividade extraclasse sugerida no minicurso introdutório foi discutida, corrigida e a solução apresentada aos estudantes conforme mostra a Figura 1.

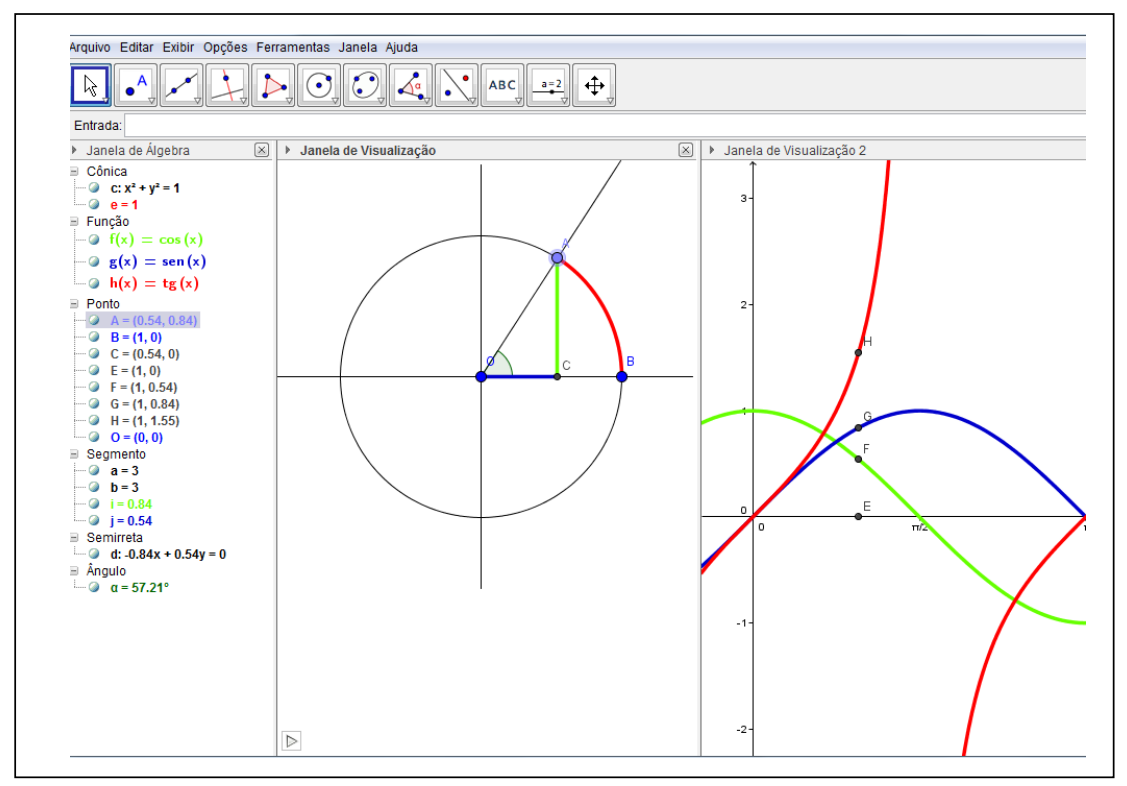

Figura 1: Construção GeoGebra: Solução Atividade Extraclasse

Nesta etapa do trabalho, o objetivo era utilizar o software GeoGebra para representar determinadas funções em uma janela de visualização $2 D$ e em seguida apresentar a superfície gerada através da revolução do gráfico da função determinada em torno do eixo das abscissas.

Além disso, visa-se explorar outras ferramentas do software de modo a possibilitar a nítida visualização da revolução da curva sobre um dos eixos, e posteriormente chegar a dedução das fórmulas de volume e área dos sólidos de revolução cilindro, cone e esfera.

Para introduzir o tema superfície e sólido de revolução, foram utilizados alguns minutos da aula para estimular a noção intuitiva dos estudantes em relação ao tema. Usando um apresentador de slides, foram mostrados aos estudantes oito imagens de objetos do seu cotidiano, onde os estudantes foram questionados sobre quais dos objetos eles reconheceriam como sólidos de revolução ou superfície de revolução, vide Figura 2.

${ }^{3}$ Disponível em: <http://ogeogebra.com.br/site/> 


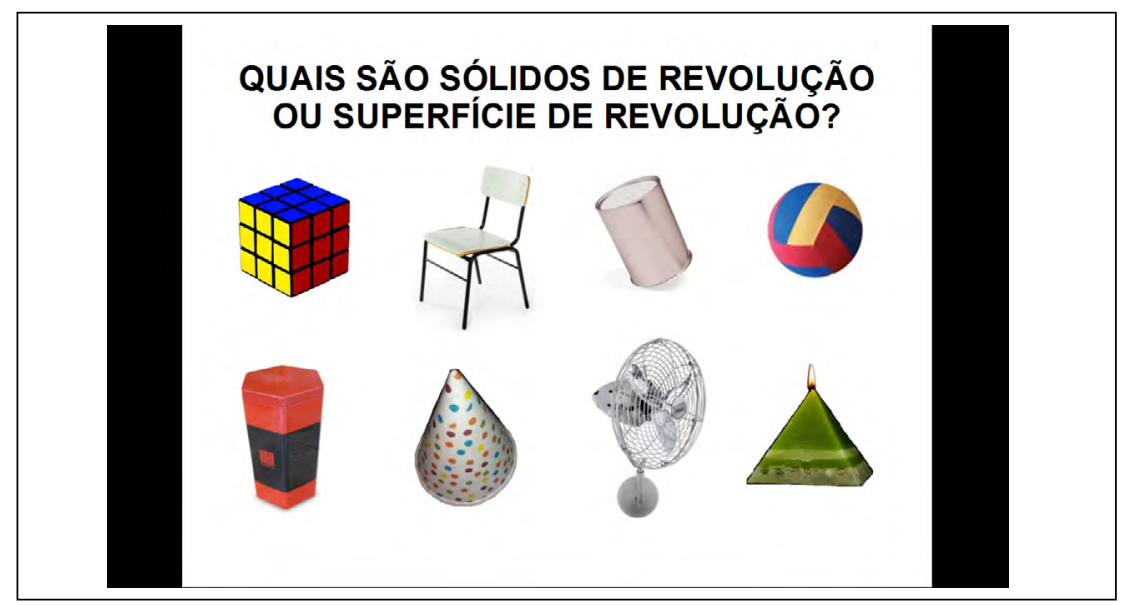

Figura 2: Objetos Cotidianos

As primeiras respostas apontaram a bola e o chapéu de aniversário como sólidos e mais tarde a lata de base circular também foi reconhecida como sólido de revolução, não sendo identificada nenhuma superfície de revolução. Em seguida, foi solicitado aos estudantes que citassem algumas características destes objetos reconhecidos como sólidos de revolução, para que a superfície fosse identificada com maior facilidade. Isso aconteceu quando foi percebido que o chapéu de aniversário era um objeto aberto, ao contrário dos outros dois objetos apontados anteriormente como sólidos de revolução.

É importante salientar que alguns objetos citados podem apresentar, dependendo da perspectiva ou critério técnico utilizado, uma análise ambígua com relação a qualificação quanto a sólido ou superfície de revolução. No entanto, o objetivo principal da atividade era estimular e amadurecer as ideias intuitivas em relação aos conceitos abordados durante a atividade.

Os estudantes foram estimulados a definirem com suas palavras o que seria um sólido de revolução e uma superfície de revolução e em seguida foi apresentada a definição matemática formal de cada item, com base no aporte teórico utilizado para o planejamento das atividades.

Dentre os objetos apresentados, dois foram destacados por possuírem em sua composição, características que lembravam superfícies de revolução, conforme apresenta a Figura 3.

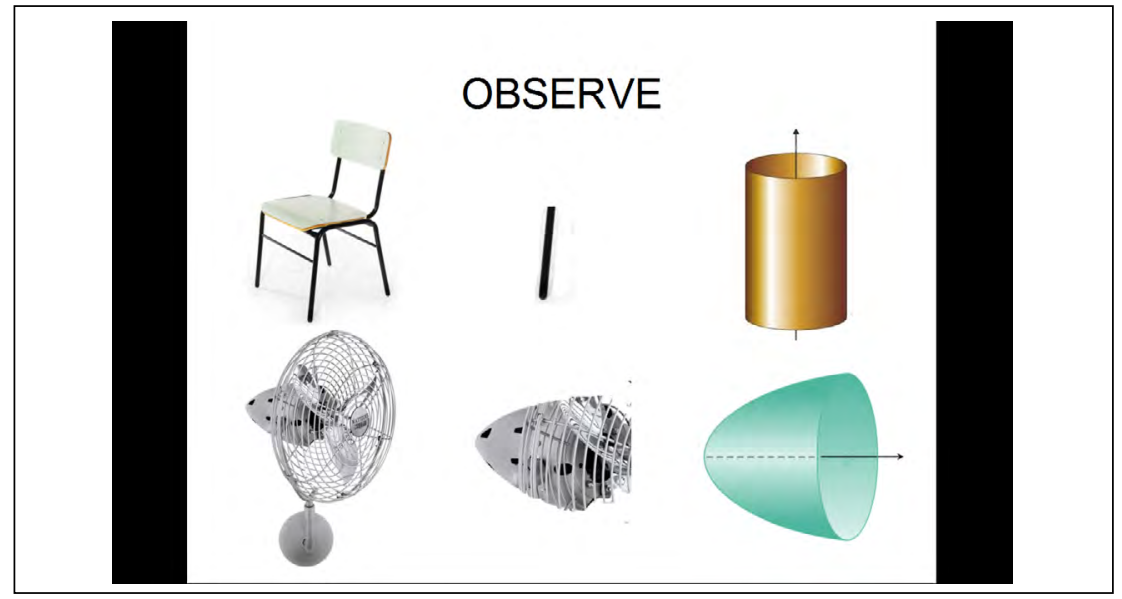

Figura 3: Partes com Características de Superfícies de Revolução

Num segundo momento da aula prática, alguns minutos foram dedicados para a parte prática da construção geométrica, onde cada estudante em um computador, criou passo a passo uma superfície cilíndrica de revolução no ambiente de matemática dinâmica do GeoGebra. Porém, antes do efetivo início da atividade, foi apresentada a superfície cilíndrica de revolução que seria construída, mostrando algumas animações geométricas para despertar a curiosidade e o interesse dos estudantes pela atividade a ser realizada.

Posteriormente, estimulando a participação dos estudantes através de uma situação-problema, foi informado inicialmente aos estudantes que pretendia-se obter uma superfície de revolução a partir de uma função $f: I \rightarrow \mathbb{R}$, 
sendo $I=[a, b]$. Os estudantes foram questionados sobre qual função poderia gerar uma superfície cilíndrica de revolução em torno do eixo das abscissas. Após intensa discussão, apareceram algumas conjecturas que após desenvolvidas e amadurecidas, transformaram-se em um consenso de que a resposta deveria ser a função constante.

Para construir a proposta de representações gráficas, para as superfícies de revolução e curvas de nível, pautandose nas indicações de Dantas e Ferreira (2016) [22], com um estudante por computador e todos com software GeoGebra aberto, solicitou-se que criassem na janela de visualização $2 D$, três controles deslizantes um com nome $a$, valor mínimo -3 , valor máximo 3 , incremento 0.1 , outro com nome $b$, valor mínimo $a$, valor máximo 5 , incremento 0.1 e o último de ângulo, com nome $m$, valor mínimo $0^{\circ}$, valor máximo $360^{\circ}$, incremento $1^{\circ}$, como ilustrado na Figura 4 .

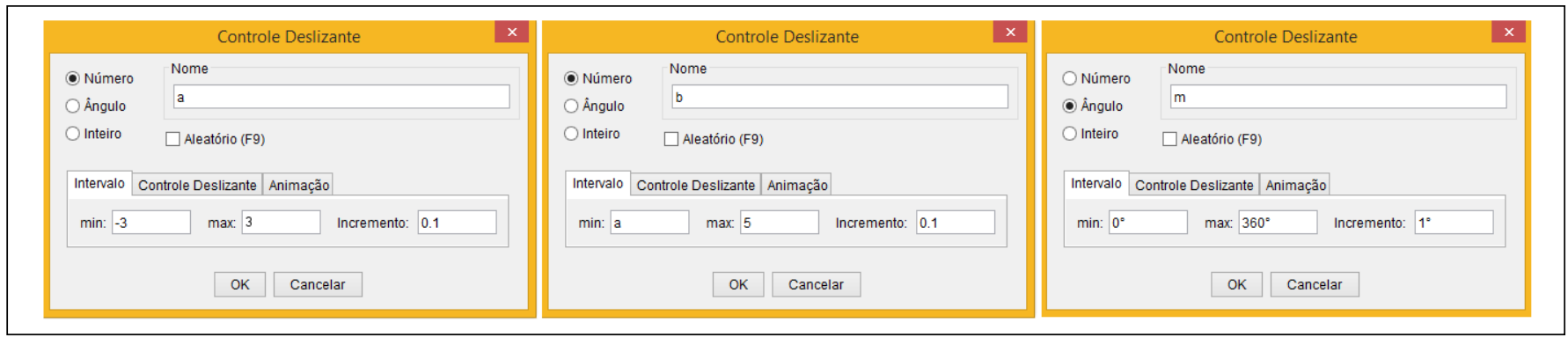

Figura 4: Construção GeoGebra: Controles Deslizantes

Foi solicitado que inserissem uma função na barra de comando Entrada, digitando a palavra função e escolhendo a $2^{a}$ opção, Função [<Função $>$, <Valor de $x$ Inicial $>,<$ Valor de $x$ Final $>$ ] e digitassem no lugar de $<$ Função $>$ a função constante escolhida, 3, no lugar de $<$ Valor de $x$ Inicial $>$ e $<$ Valor de $x$ Final $>$ o valor inicial e final do domínio da função. Em seguida, os estudantes foram orientados a abrir a Janela de visualização 3D, clicando em menu Exibir e no submenu Janela de Visualização 3D.

Após concluída a construção, os estudantes foram instruídos a explorarem os controles deslizantes $a$ e $b$, para que pudessem observar em duas e em três dimensões a variação da função a medida que alterassem os valores do domínio da função, através dos controles deslizantes, conforme ilustrado na Figura 5.

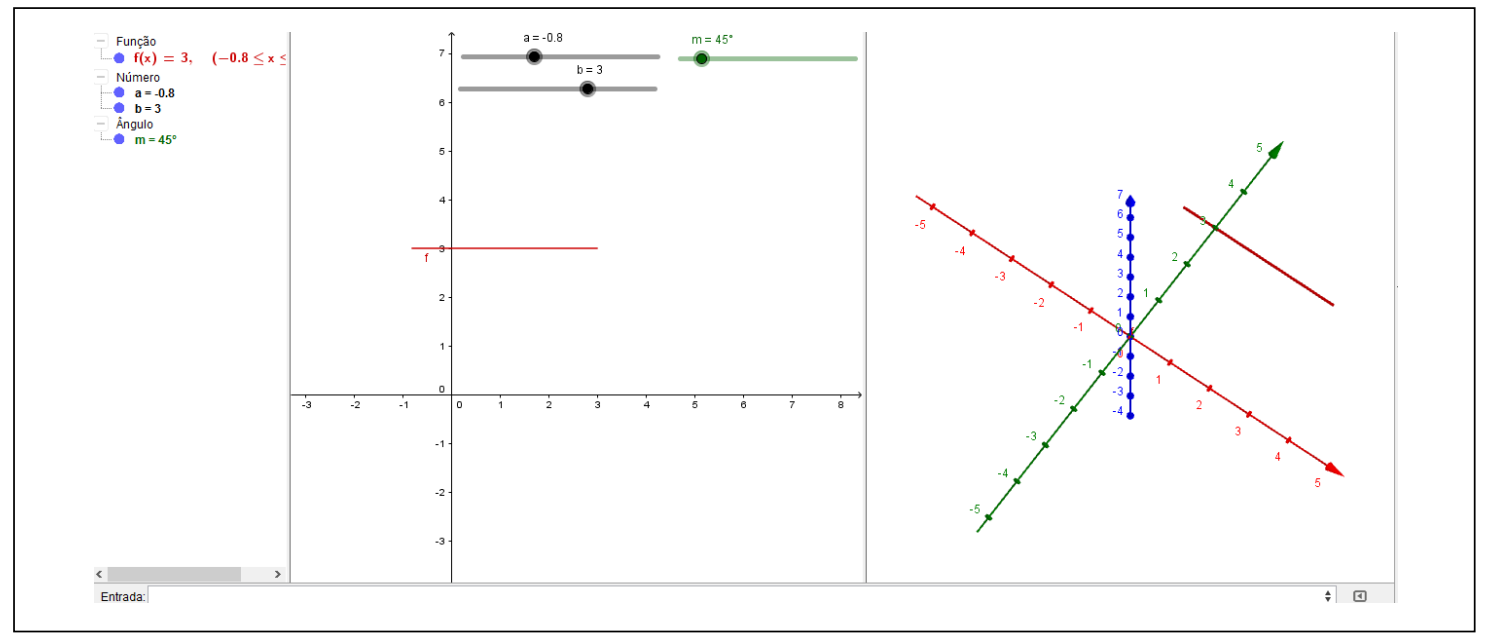

Figura 5: Construção GeoGebra: Visualização do Gráfico em 2D e 3D

Continuando esta atividade, foi solicitado aos estudantes que na barra de comando Entrada digitassem a palavra "superfície" e a partir das opções sugeridas pelo software, escolhessem a primeira opção disponível para o comando Superfície, tal como ilustrado na Figura 6.

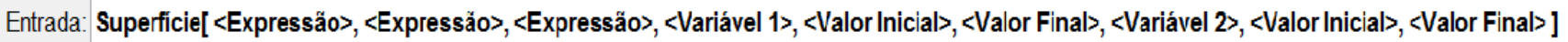


E em seguida, foi sugerido que alterassem os dados de forma a obterem a configuração apresentada na Figura 7.

$$
\text { Entrada: Superficie }\left[t, f(t) \cos (\theta), f(t) \operatorname{sen}(\theta), t, a, b, \theta, 0^{\circ}, m\right]
$$

Figura 7: Construção GeoGebra: Comando Superfície

Foi esclarecido aos estudantes que as informações sobre as especificidades matemáticas do funcionamento da parametrização seriam apresentadas na aula seguinte, pois aquele era um momento de ênfase na visualização da superfície de revolução. Com isso, foi construída uma superfície cilíndrica de revolução em torno do eixo das abscissas, com possibilidade de visualização desta revolução através da utilização de ferramentas do software, onde durante a construção os estudantes tiveram a disposição constante auxílio de dois tutores e todos conseguiram finalizar com sucesso a atividade.

Por fim, os estudantes foram estimulados a realizar animações, a explorar os controles deslizantes e a movimentação da janela de visualização 3D. Além disso foi proposto aos mesmos que definissem superfície cilíndrica de revolução e, após algumas conjecturas, foi apresentada a definição formal. Algumas construções citadas estão ilustradas na Figura 8.

Visando facilitar o entendimento da parte que envolve conceitos de Cálculo Diferencial e Integral na dedução das fórmulas de volume e área do cilindro, cone e/ou esfera, as quais seriam trabalhadas em aulas posteriores, foi construída com os estudantes as curvas de nível da superfície cilíndrica de revolução, para que fosse possível visualizar qual seria a figura formada pela interseção da superfície revolução mencionada com um ou vários planos perpendiculares ao eixo de rotação.

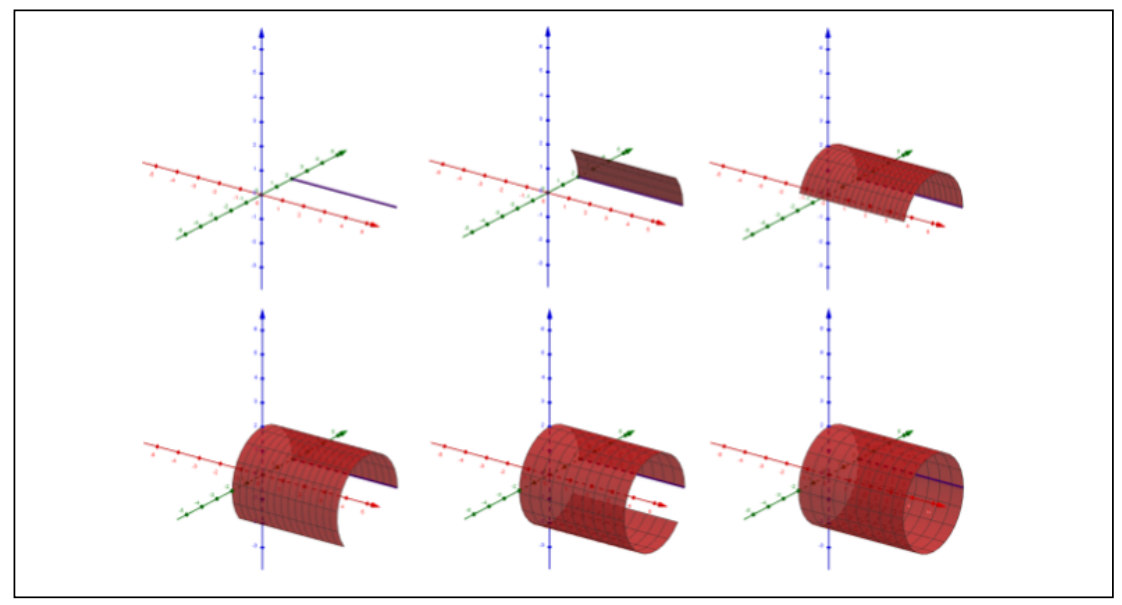

Figura 8: Construção GeoGebra: Superfície Cilindra de Revolução

Assim, foi pedido aos estudantes que criassem na janela de visualização $2 D$, dois controles deslizantes, um com nome $n$, inteiro, valor mínimo 0 , valor máximo 60, incremento 1 , outro do tipo ângulo, com nome $o$, valor mínimo $0^{\circ}$, valor máximo $360^{\circ}$, incremento $1^{\circ}$. Dando sequência, foi solicitado que inserissem uma função digitando na barra de comando Entrada a palavra "Sequência", dentre as opções apresentadas escolhessem a terceira e em $<$ Expressão $>$ digitassem "Curva", logo após selecionassem a segunda opção, obtendo assim o comando ilustrado na Figura 9.

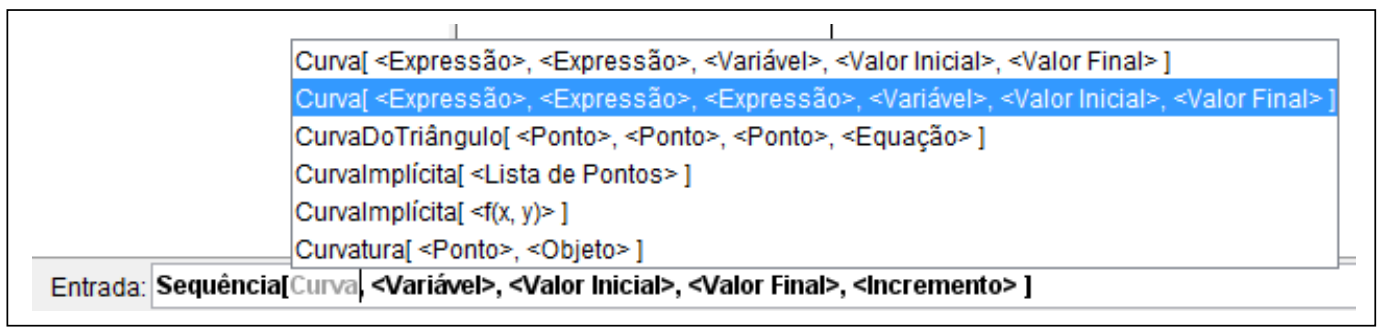

Figura 9: Construção GeoGebra: Comando Sequência Conjugado com o Comando Curva 
Em seguida, alterassem os dados, obtendo o comando Sequência[Curva[i, $\left.f(i) \cos (\theta), f(i) \sin (\theta), t, 0^{\circ}, o\right], i, a, b$, $a b s(a-b) / n]$, o qual gerou as curvas representadas na Figura 10.

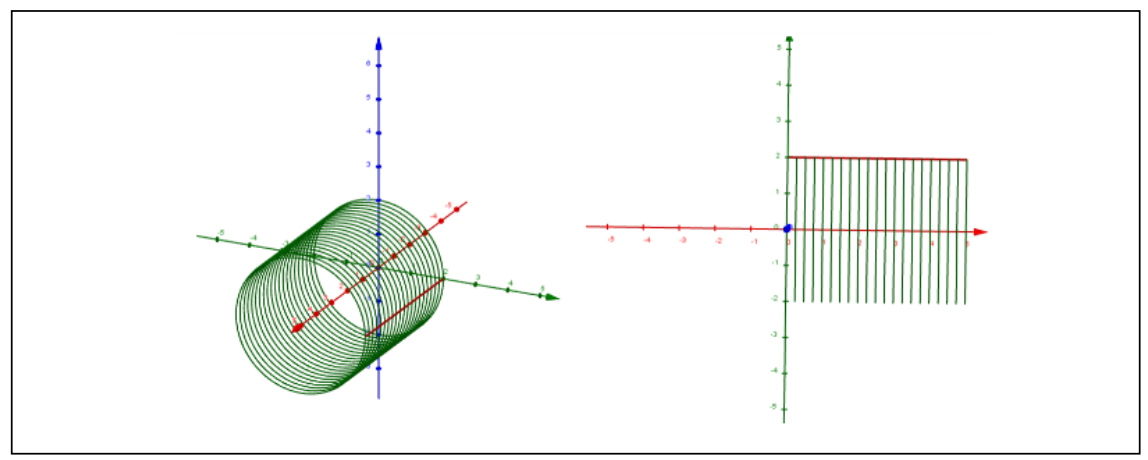

Figura 10: Construção GeoGebra: Curvas de Nível da Superfície Cilindra de Revolução

Após a construção foi apresentada a possibilidade de visualização de outra superfície de revolução a partir da construção feita pelos estudantes, com a alteração apenas da função. Como exemplo, foi alterada a função constante $f(x)=3$, para $f(x)=2 \cdot \sqrt{1-\frac{x^{2}}{9}}$, obtendo assim uma superfície elíptica de revolução, vide Figura 11.

Para complementar a atividade e, com intuito de ampliar a possibilidade de visualização da rotação de uma função para gerar uma superfície de revolução, foi proposto aos estudantes que em vinte minutos e a partir da construção feita anteriormente, alterassem a função, de forma a obter uma superfície cônica de revolução e uma superfície esférica de revolução.

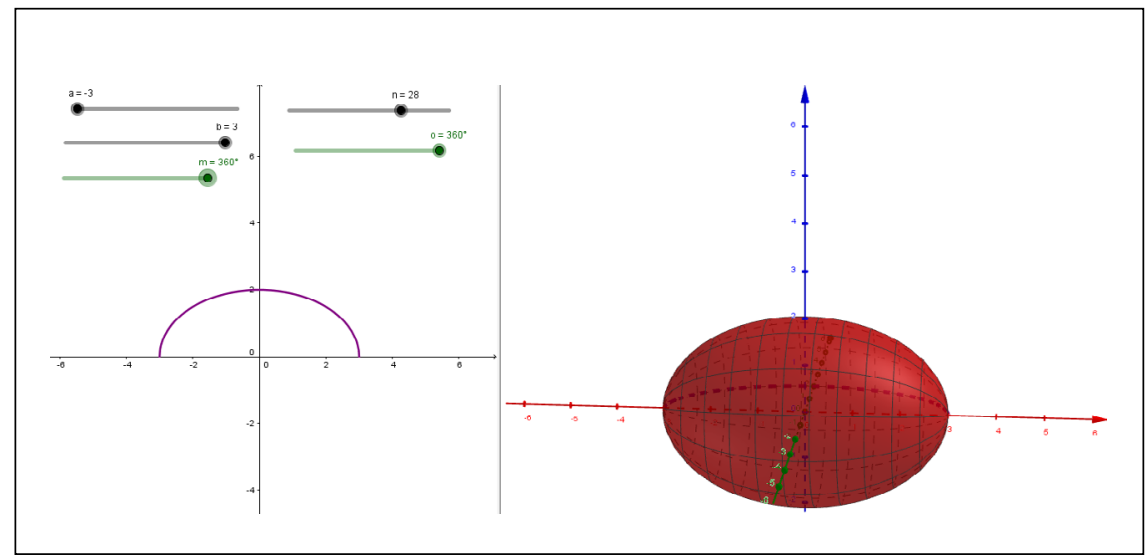

Figura 11: Construção GeoGebra: Superfície Elíptica de Revolução

Dando sequência à atividade, também foi pedido aos estudantes que tentassem definir o que é uma superfície cônica de revolução, superfície esférica de revolução, definir um cone de revolução e uma esfera de revolução. Para finalizar, foram apresentadas pelo grupo as definições matemáticas formais. Segue nas Figuras 12 e 13 imagens das superfícies propostas.

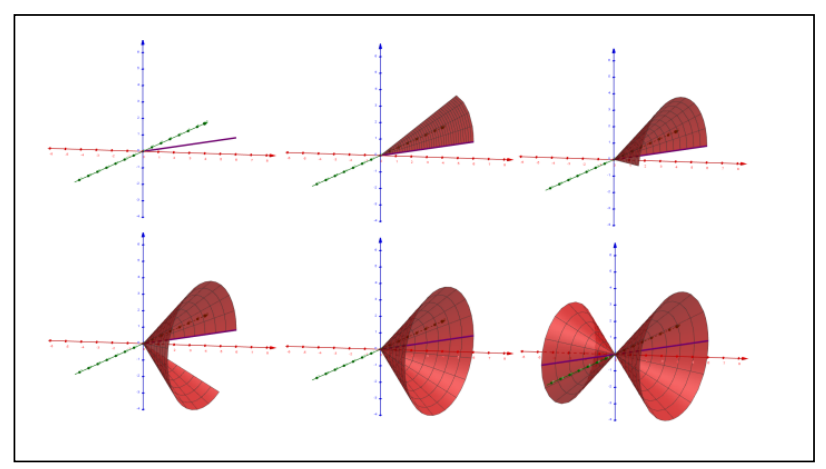

Figura 12: Construção GeoGebra: Superfície Cônica de Revolução 


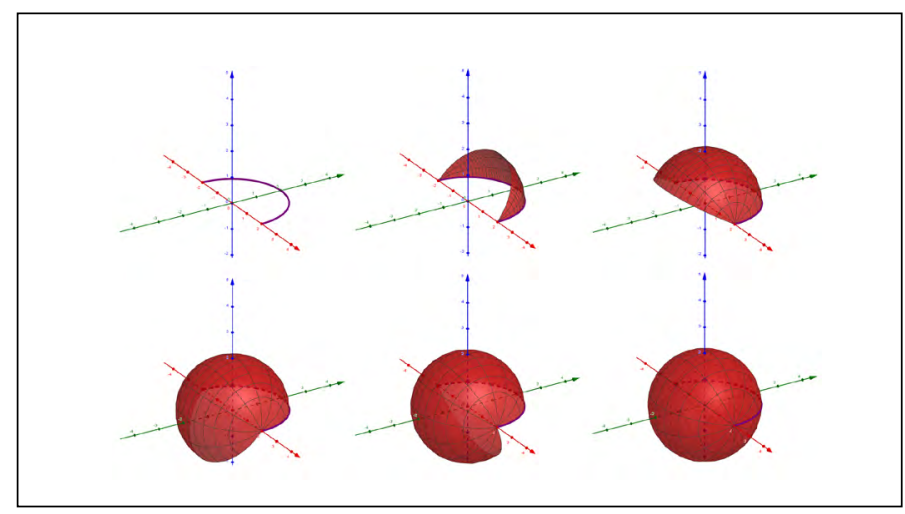

Figura 13: Construção GeoGebra: Superfície Esférica de Revolução

\subsection{A aula teórica}

\subsubsection{Formalização dos conceitos abordados na Aula Prática}

Na terceira aula, dando prosseguimento a sequência didática, durante os primeiros 15 minutos, foi promovida uma explicação de alguns conceitos matemáticos que foram utilizados na oficina de construção das superfícies de revolução.

Inicialmente, foi questionado aos estudantes sobre qual comando utilizado no GeoGebra faria com que a curva da função fizesse uma rotação em torno de um dos eixos $X, Y$ ou $Z$. A maioria dos estudantes responderam que era o comando Superfície, o que não está errado, porém ninguém observou que a parametrização utilizada nos três primeiros campos do comando "Superfície $\left[t, f(t) \cdot \cos (\theta), f(t) \cdot \sin (\theta), t, a, b, \theta, 0^{\circ}, m\right]$ " era o que definiria a rotação.

Em seguida, usando como recursos quadro e pincel, foi feito a seguinte demonstração que provava o fato da curva rotacionar em torno do eixo $X$, neste caso.

\section{Demonstração:}

Seja, $x=t, y=f(t) \cdot \cos (\theta)$ e $z=f(t) \cdot \sin (\theta)$, então fazendo $y^{2}+z^{2}$, obtêm-se:

$$
\begin{gathered}
\left.y^{2}+z^{2}=(f(t)) \cdot \cos (\theta)\right)^{2}+(f(t) \cdot \sin (\theta))^{2} \\
y^{2}+z^{2}=(f(t))^{2} \cdot\left(\sin ^{2}(\theta)+\cos ^{2}(\theta)\right)
\end{gathered}
$$

Pela relação fundamental da trigonometria temos que, $\sin ^{2}(\theta)+\cos ^{2}(\theta)=1$ e como $x=t$, segue que:

$$
\begin{aligned}
& y^{2}+z^{2}=f(t)^{2} \\
& y^{2}+z^{2}=f(x)^{2}
\end{aligned}
$$

Daí, pode-se concluir que a equação acima descreve uma circunferência de raio $f(x)$, ou seja, a intersecção do plano $x=c$ com a superfície gerará uma circunferência de raio $f(c)$, mostrando que o gráfico da função foi rotacionado em torno do eixo das abscissas.

Analogamente, pode-se obter uma rotação em torno do eixo $Y$, fazendo $y=t, x=f(t) \cdot \cos (\theta)$ e $z=f(t) \cdot \sin (\theta)$, ou em torno do eixo $Z$, fazendo $z=t, x=f(t) \cdot \cos (\theta)$ e $y=f(t) \cdot \sin (\theta)$, tais fatos podem ser observados na Figura 14.

Após a demonstração matemática, foi feita uma complementação, onde o estudante pode observar que para qualquer ponto $c$ pertencente ao domínio da função, temos que a interseção do plano $x=c$ (perpendicular ao eixo das abscissas) com a superfície obtida, geraria uma circunferência, vide Figura 15. 


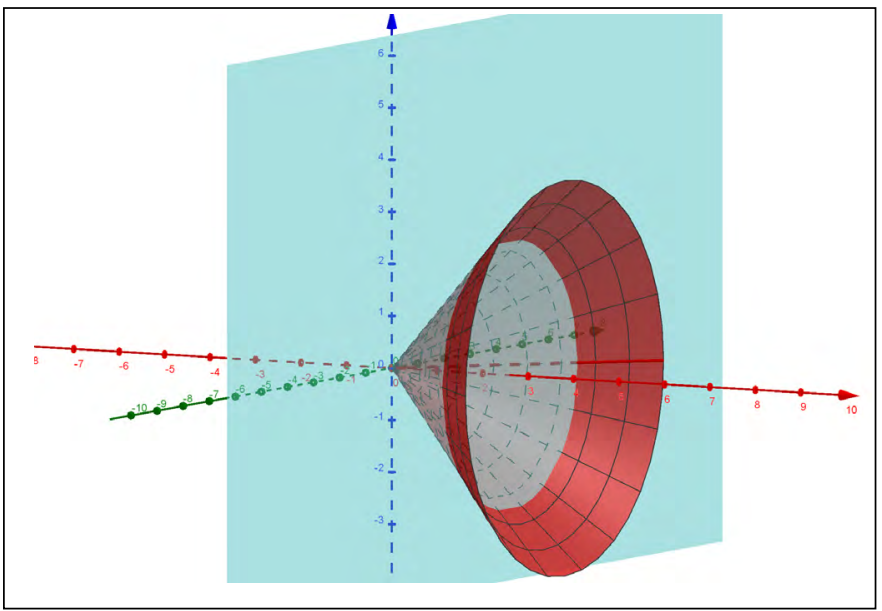

Figura 14: Construção GeoGebra: Interseção do Plano $x=$ c e a Superfície Cônica

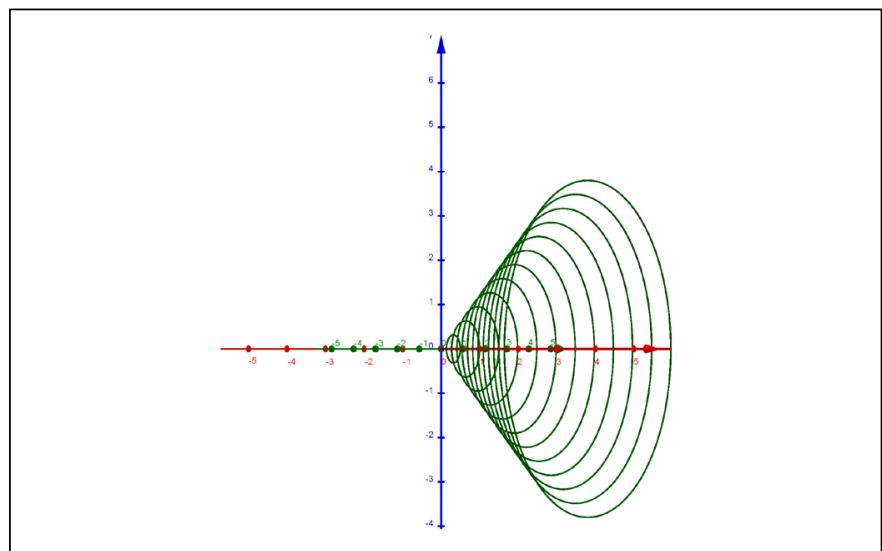

Figura 15: Construção GeoGebra: Curvas de nível da Superfície Cônica

Tal fato foi visualizado na seção de Aula prática (seção 3.2), onde foram construídas as curvas de nível da superfície obtida. A explicação destes conceitos foi de suma importância para que os estudantes entendessem os conceitos matemáticos abordados na oficina de cálculo de volumes de sólidos utilizando o conceito de integral.

Ainda como suporte a oficina que viria, após a formalização dos conceitos matemáticos, foram destinados 15 minutos para demonstrar matematicamente como calcular o volume do cilindro usando o Princípio de Cavalieri ${ }^{4}$. Porém, antes de iniciar a demonstração, foi mostrado no GeoGebra para os estudantes que o cilindro pode ser obtido a partir de um prisma cuja base é um polígono regular de $n$ lados, fazendo $n$ tender ao infinito. Para isto, foi criado um cilindro e um prisma cuja base era um polígono regular de $n$ lados inscrito num círculo de mesmo raio que o do cilindro, onde em um controle deslizante o discente poderia variar $n$ de 3 à 100. Ao aumentar o valor de $n$, observa-se que os sólidos tendem a ser iguais, conforme na Figura 16.

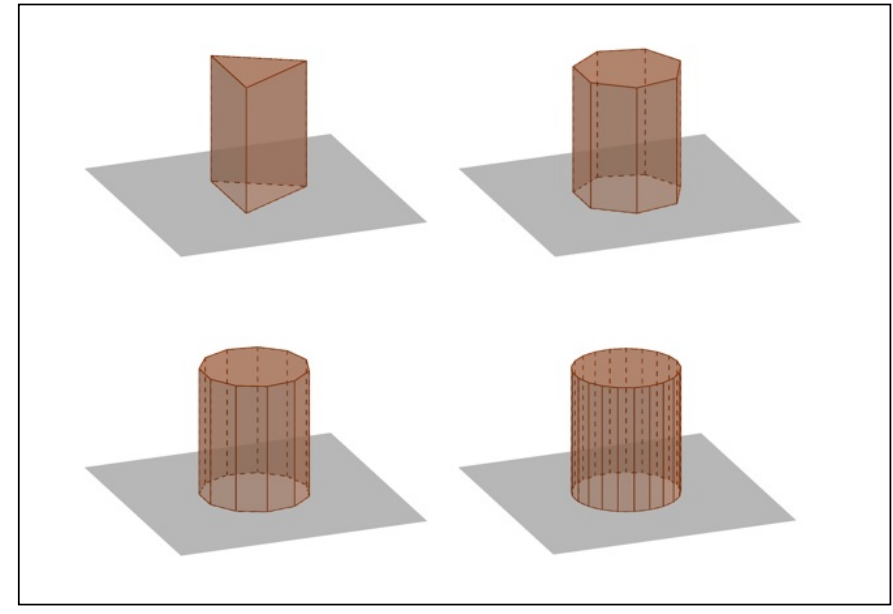

Figura 16: Construção GeoGebra: Prisma para Cilindro 
Logo após esta etapa, foi demonstrado que o volume do cilindro é igual ao volume do prisma, para isto, foi utilizado o Princípio de Cavalieri e o software GeoGebra para fazer as animações. O recurso de área e volume do GeoGebra foi de extrema importância, pois os estudantes puderam notar que se as áreas das secções obtidas da interseção do plano $z=c$, onde $c$ é uma constante qualquer, com os dois sólidos são iguais, então os volumes são iguais. A demonstração do volume do cilindro teve como objetivo auxiliar e preparar os estudantes para a próxima oficina, onde os mesmos precisariam de uma forma de calcular o seu volume, como pode ser visto na Figura 17.

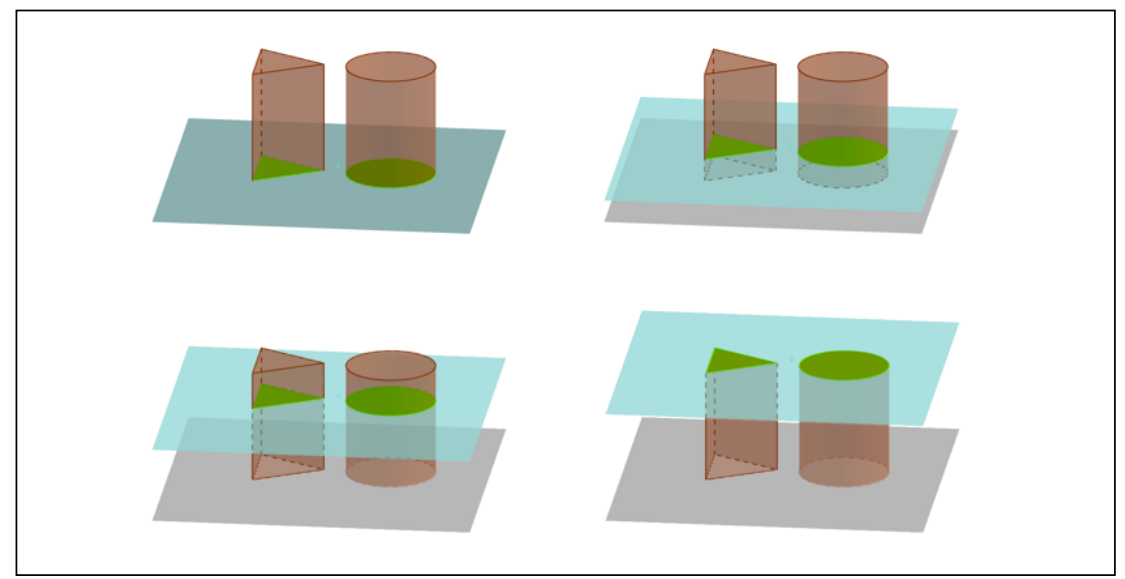

Figura 17: Construção GeoGebra: Princípio de Cavalieri

Em seguida, foram destinados 10 minutos para os estudantes trabalharem os conceitos de área da superfície cilíndrica e cônica de revolução, onde foram apresentadas animações das planificações de objetos matematicamente similares e formalizados matematicamente esses conceitos, conforme Figuras $18^{5}$ e 19.

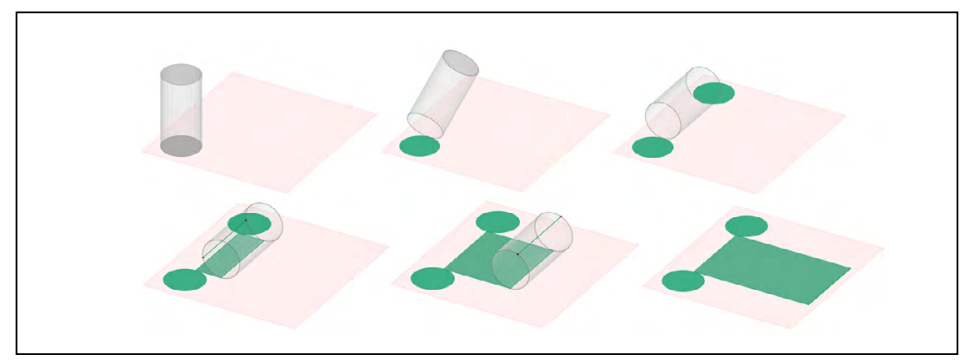

Figura 18: Construção GeoGebra: Planificação Cilindro de Revolução

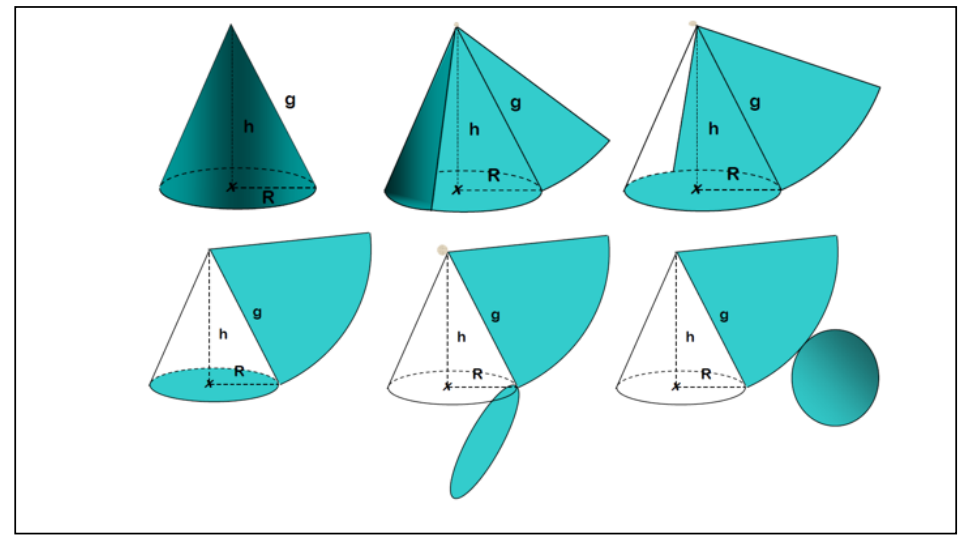

Figura 19: Planificação do Cone usando Editor de Slides

\footnotetext{
${ }^{4}$ O Princípio de Cavalieri consiste na afirmação de que se dois sólidos de mesma altura, têm secções iguais para quaisquer planos paralelos as suas bases, então necessariamente esses sólidos possuem volumes iguais.

${ }^{5}$ Criado por Carla Rentes, disponível em: <https://www.geogebra.org/b/tXQb4kWF\#material/wj2gKyAa>. Acesso em: 09 abr. 2016.
} 


\subsubsection{Formalização dos conceitos de volume dos sólidos de revolução}

Dando prosseguimento a parte teórica da intervenção, foram utilizados 20 minutos para a recapitulação, em parceria com os estudantes, do conceito formal de integral definida por somas de Riemann, de forma que primeiramente foi minuciosamente explicado e ilustrado, com apresentações de slides usando a suíte de aplicativos LibreOffice e computadores do laboratório de informática, a ideia de partição de um intervalo e o conceito de intervalo equiparticionado, vide Figura 20.

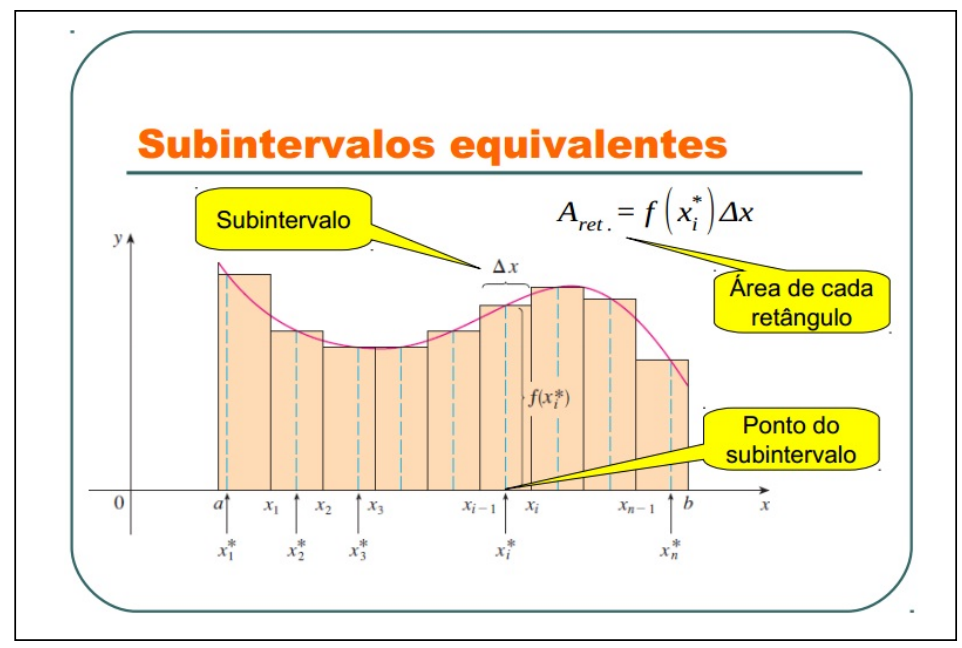

Figura 20: Slide de Aula de Introdução à Somas de Riemann

Em seguida, tomando exemplos de funções reais contínuas de domínio $[a, b] \subset \mathbb{R}$, foram introduzidos, usando o software de matemática dinâmica GeoGebra, retângulos entre o gráfico da função e o eixo das abscissas, onde, com a variação de um controle deslizante no software, era possível para os estudantes alterarem a quantidade de retângulos na construção. Contudo, é importante salientar que a alteração somente se processava de maneira matematicamente vinculada ao valor da amplitude de cada subintervalo gerado com a partição do intervalo original e a função definida na construção, onde o valor de cada subintervalo era igual e valia $\frac{b-a}{n}$ e cada intervalo era base de um, e somente um retângulo, cuja altura correspondia ao valor da função em algum ponto dentro do respectivo subintervalo, conforme ilustrado na Figura 21.

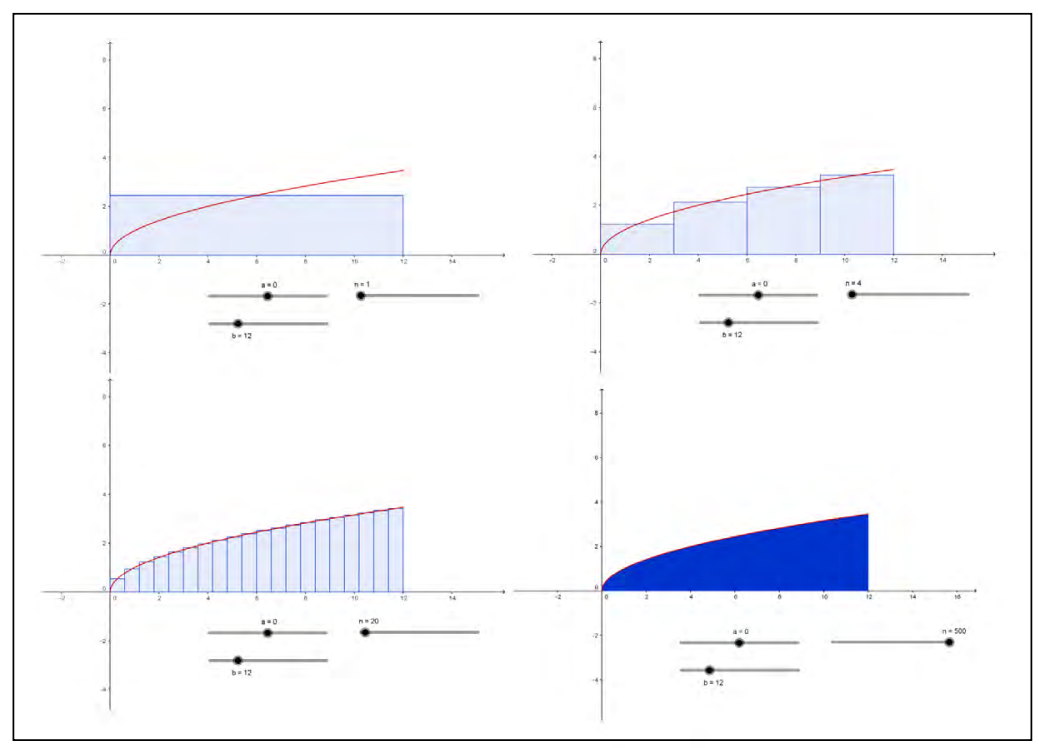

Figura 21: Construção GeoGebra: Integral Definida 
Logo após esta etapa, os estudantes foram incentivados a manipular os controles deslizantes e dados da função da construção e a partir de suas observações, estabelecerem conjecturas a respeito da relação matemática entre o tamanho de cada intervalo, a área dos retângulos em comparação a área delimitada pelo gráfico da função e o eixo das abscissas no intervalo e o número de retângulos inseridos.

Cabe ressaltar que cada estudante estava trabalhando em um computador individual, com todos os arquivos das construções disponíveis e monitorados constantemente. Além disso, se mostravam bastante dispostos e animados com a interação com o software e identificaram com certa facilidade as relações matemáticas existentes entre os entes em questão.

Finalizando a recapitulação, foi feita a formalização dos conceitos e sanadas todas as dúvidas que persistiram até aquele momento, vide Figura 22.

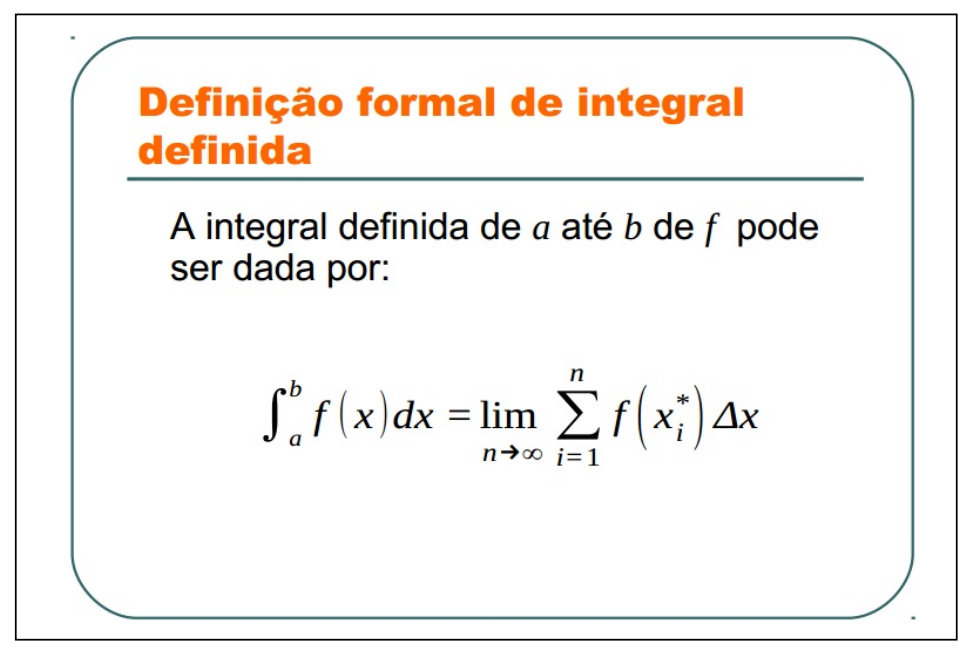

Figura 22: Slide de Aula de Formalização de Integral Definida

Continuando a atividade, foi iniciado o próximo assunto da intervenção que consistia em introduzir a ideia de volume de sólidos de revolução. Assim, novamente intermediado por ilustrações animadas e interativas do software GeoGebra, sob as mesmas circunstâncias da etapa anterior, foram destinados 10 minutos para trabalhar aproximações dos volumes de alguns sólidos de revolução por meio de cilindros ${ }^{6}$, em que em um controle deslizante da construção disponível aos estudantes, os mesmos poderiam, dentre outras modificações, aumentar a quantidade de cilindros em detrimento da diminuição da altura ${ }^{7}$ desses objetos, de acordo com ilustração da Figura 23.

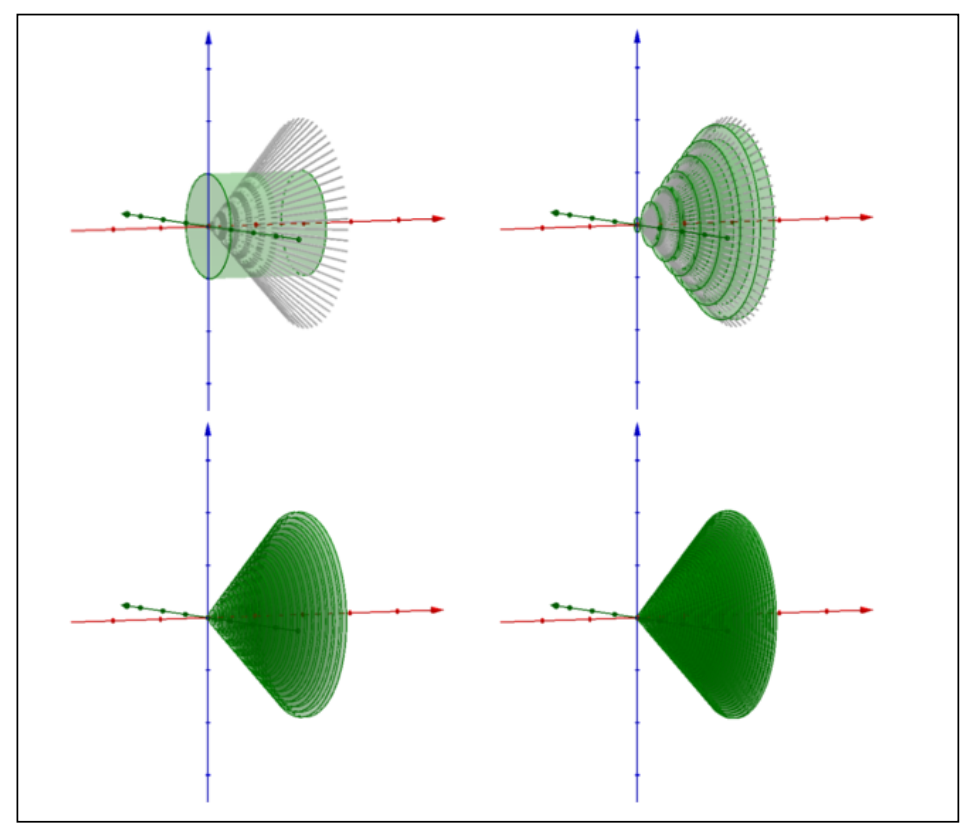

Figura 23: Construção GeoGebra: Aproximação do Volume de um Cone de Revolução por 1, 7, 20 e 40 Cilindros de Mesma Altura

\footnotetext{
${ }^{6}$ Neste trabalho, cilindro é abreviação de notação do objeto matemático cilindro de revolução.
} 
Em seguida, novamente estimulando a participação dos estudantes, foram utilizados 20 minutos para o desenvolvimento de ideias intuitivas concernentes aos conceitos matemáticos pertinentes. E, por conseguinte, formalizado, usando como recurso o quadro e o pincel, os conceitos relacionados ao volume de sólidos de revolução da seguinte forma:

Considerando inicialmente um sólido obtido através da revolução do gráfico de uma função integrável $g: I \rightarrow \mathbb{R}$, com $I \subset \mathbb{R}$, em torno do eixo das abscissas, $n$ o número de cilindros usados para aproximar o volume deste sólido, da forma vista durante a etapa anterior, $\Delta x$ a altura de cada cilindro e observando que $g\left(x_{i}^{*}\right)$ é aproximadamente o valor do raio da círculo da base de cada cilindro, segue que:

$$
\text { Volume do sólido }=V \approx \sum_{i=1}^{n} \pi g^{2}\left(x_{i}^{*}\right) \Delta x
$$

Daí, definindo uma função $f: I \rightarrow \mathbb{R}$, tal que $f(x)=g^{2}(x)$, para todo $x \in I$, tem-se:

$$
V \approx \sum_{i=1}^{n} \pi g^{2}\left(x_{i}^{*}\right) \Delta x=\sum_{i=1}^{n} \pi f\left(x_{i}^{*}\right) \Delta x=\pi \sum_{i=1}^{n} f\left(x_{i}^{*}\right) \Delta x
$$

Onde, considerando o limite quando $n$ tende ao infinito e usando o conceito formal de integral definida, segue que:

$$
V=\pi \int_{a}^{b} f(x) d x=\pi \int_{a}^{b} g^{2}(x) d x
$$

Portanto,

$$
V=\pi \int_{a}^{b} g^{2}(x) d x
$$

Cabe salientar que após encontrada matematicamente a fórmula genérica para o cálculo do volume de sólidos de revolução, foram deduzidas as fórmulas, ainda contando com a participação direta de todos os estudantes, de se calcular o volume do cone de revolução, dadas sua altura e o raio da base e da esfera, a partir do raio da mesma.

E, finalizando a intervenção, durante os últimos 10 minutos foram explanadas aplicações práticas da teoria matemática estudada. Em um primeiro momento foi importada uma foto de perfil de um barril ${ }^{8}$ para a janela de visualização 2D do GeoGebra e a partir dela e da identificação de que o barril tem características de um sólido de revolução foi encontrada, usando recursos do software, uma função de uma variável. Quando rotacionada em torno do eixo das abscissas, tal figura geraria uma superfície de revolução cujas propriedades eram capazes de descrever satisfatoriamente várias das características geométricas do objeto real, conforme pode ser visto nas ilustrações presentes nas Figuras 24 e 25.

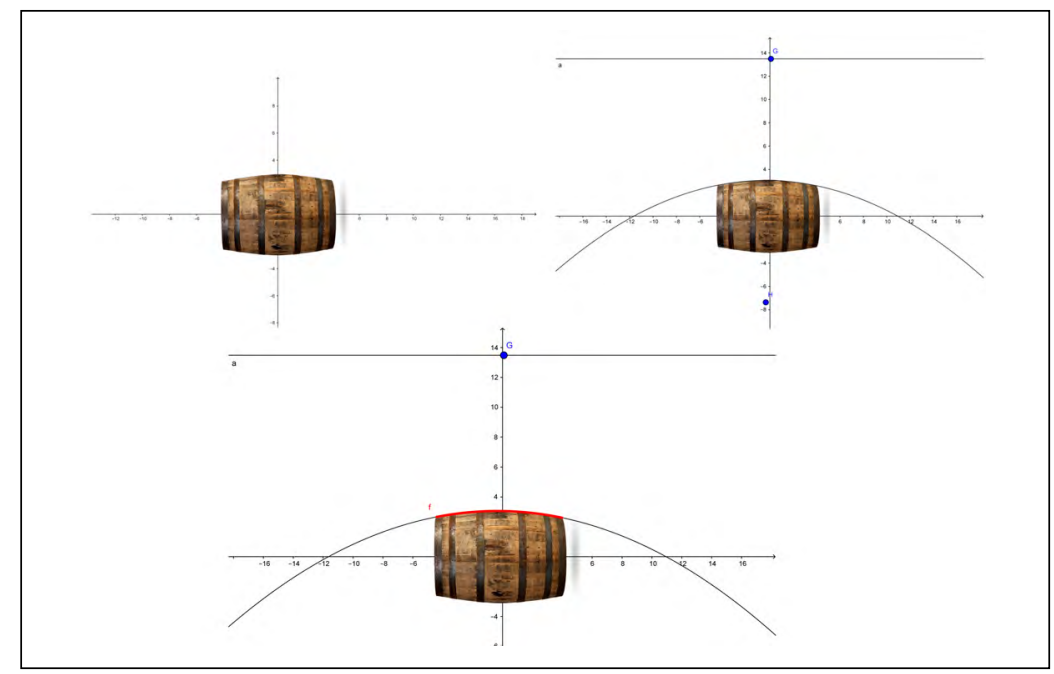

Figura 24: Construção GeoGebra: Três Primeiras Etapas da Modelagem do Barril Fonte figura do barril: The Spirits Bureau

\footnotetext{
${ }^{7}$ Neste trabalho, toma-se como altura do cilindo a distância entre os centros dos círculos que o compõem.
} 


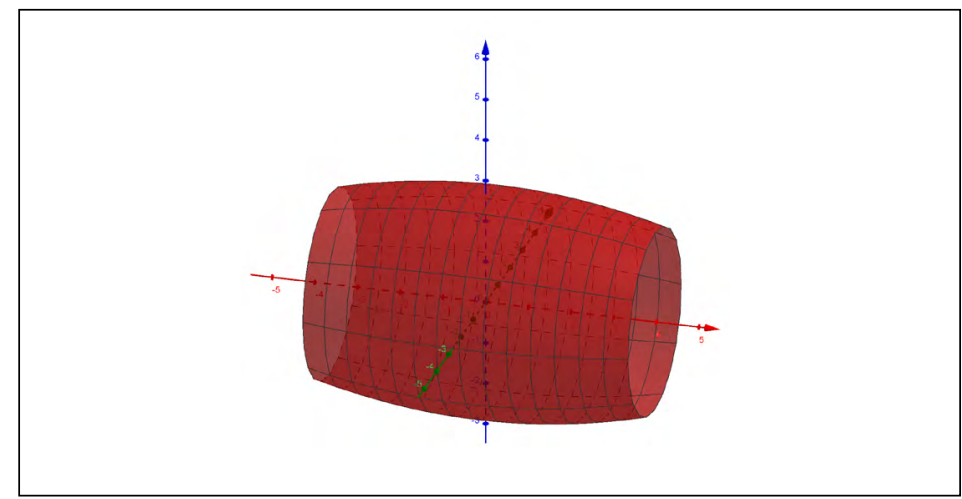

Figura 25: Construção GeoGebra: Produto Final da Modelagem do Barril

\section{Análise dos resultados}

Para análise dos resultados quanto às avaliações diagnósticas, foram adotados os seguintes critérios:

1. Foi instituída uma pauta de correção, confeccionada da seguinte forma:

- Foram dados valores de 0 a 5 para cada questão, onde a nota 5 foi atribuída para a questão em que o estudante demonstrasse de maneira clara ter total conhecimento sobre o tema;

- Nota 4, quando o estudante apontasse deter o conhecimento, porém não se expressasse de maneira clara e/ou correta;

- Nota 3, quando o estudante demonstrasse ter um conhecimento intermediário e se expressasse de maneira clara e/ou correta;

- Nota 2, quando o estudante demonstrasse ter um conhecimento intermediário e não se expressasse de maneira clara e/ou correta.

- Nota 1, quando demonstrasse ter conhecimento raso sobre o assunto;

- Nota 0, quando demonstrasse não ter conhecimento algum, ou não respondesse;

2. As provas receberam números de identificação de 1 à 7 ;

3. De acordo com a pauta, cada um dos três membros do grupo corrigiu as provas atribuindo valores entre 0 e 5 para cada questão;

4. Foi calculada a média aritmética simples das notas de cada questão;

5. Por fim, usando média aritmética simples, foi comparado o rendimento dos estudantes em relação as avaliações diagnósticas a priori e a posteriori aplicadas a turma, para dimensionar objetivamente a eficácia da intervenção.

Após procedidas às correções, foram adotados métodos inerentes à Engenharia Didática para estudos pormenorizados dos dados obtidos, em que os mesmos foram inferidos de modo geral, marginal, contextualizado e específico, sempre subsidiados por mecanismos da análise estatística.

Para uma análise geral dos resultados obtidos, foi feita a média aritmética simples das notas obtidas por todos os estudantes da turma em cada avaliação diagnóstica, conforme aponta a Figura 26.

Com base na comparação dos resultados obtidos, foi possível verificar um aumento de 28,96\% no aproveitamento geral da turma, o que sugere que a intervenção, sob uma perspectiva geral, teve uma influência positiva no aprendizado dos estudantes.

Quanto ao estudo contextualizado, foram consideradas as condições que os estudantes normalmente vivenciavam em sua vida acadêmica com relação ao índice de aproveitamento mínimo e os métodos de avaliação de aprendizado. Assim, foi estipulado um aproveitamento de $60 \%$ como cota para separação de classes e, posteriormente realizada a análise comparativa dos resultados obtidos com a avaliação diagnóstica a priori e a avaliação diagnóstica $a$ posteriori, conforme apontam os resultados apresentados nas Figuras 27 e 28.

\footnotetext{
${ }^{8}$ Disponível em: <https://thespiritsbureau.wordpress.com/tag/rare>, acessado em: 16/03/2016.
} 


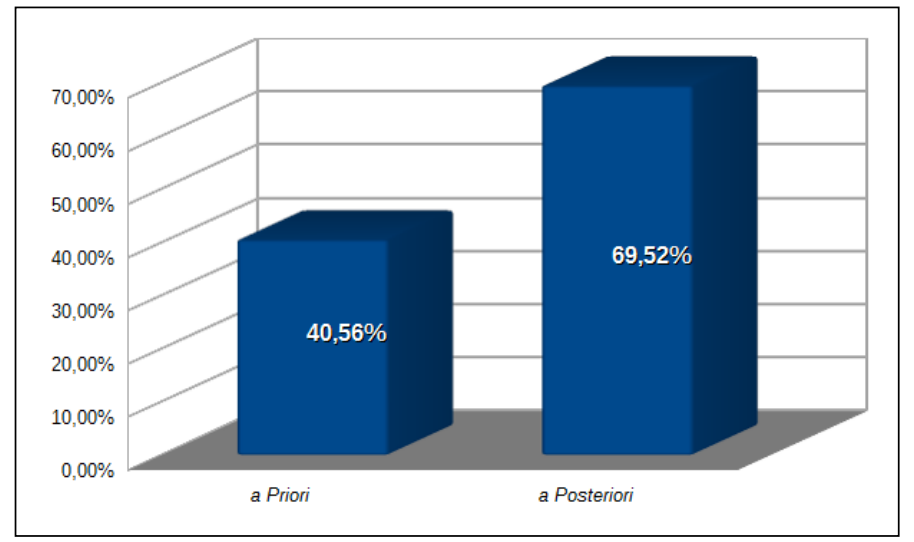

Figura 26: Gráfico Aproveitamento Geral nas Avaliações Diagnósticas

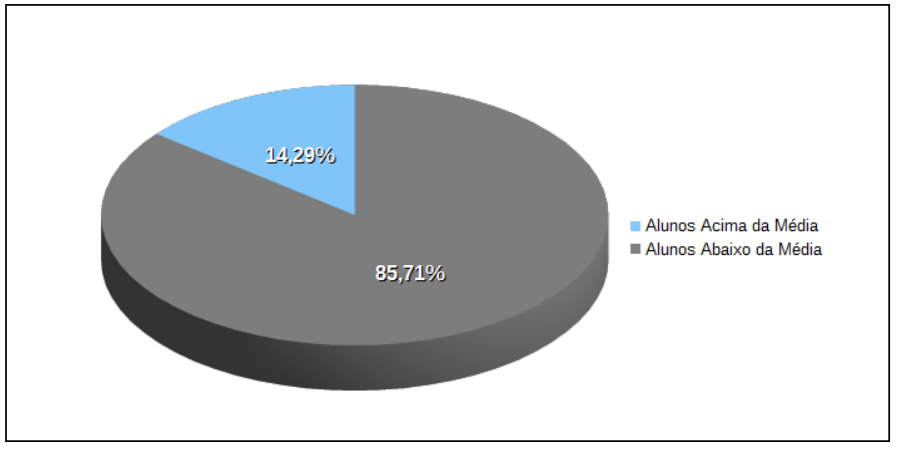

Figura 27: Gráfico Análise do Percentual de Estudantes em Relação a Média de 60\% na Avaliação a Priori

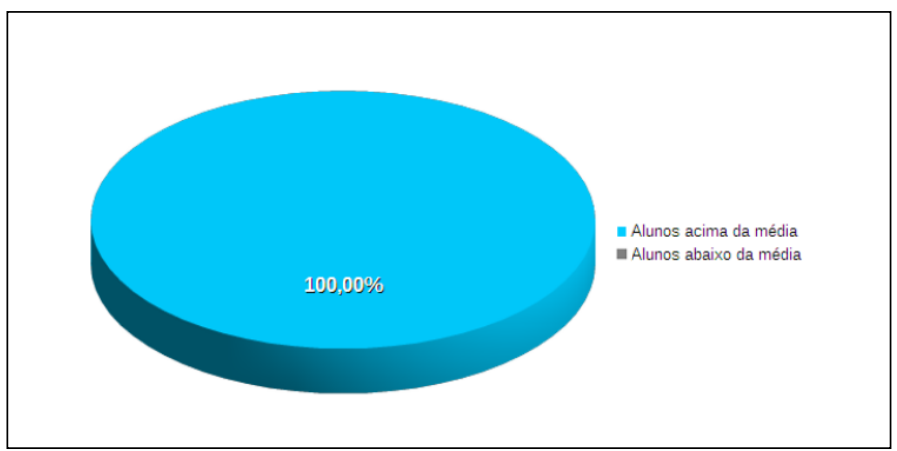

Figura 28: Gráfico Análise do Percentual de Estudantes em Relação a Média de 60\% na Avaliação a Posteriori

Como na análise das avaliações diagnósticas a priori e a posteriori foi identificado que cerca de 85,71\% dos estudantes estavam abaixo da média estipulada e, após a intervenção, 100\% dos estudantes estavam acima da média estipulada. Neste sentido, ficou claro a partir da mensuração direta a eficácia da intervenção, sob a ótica supramencionada.

Buscando observar o efeito da intervenção nos extremos, foi realizada uma análise mais detalhada dos dados de forma a comparar a maior e a menor notas obtidas nas avaliações a priori e a posteriori, vide Figura 29. 


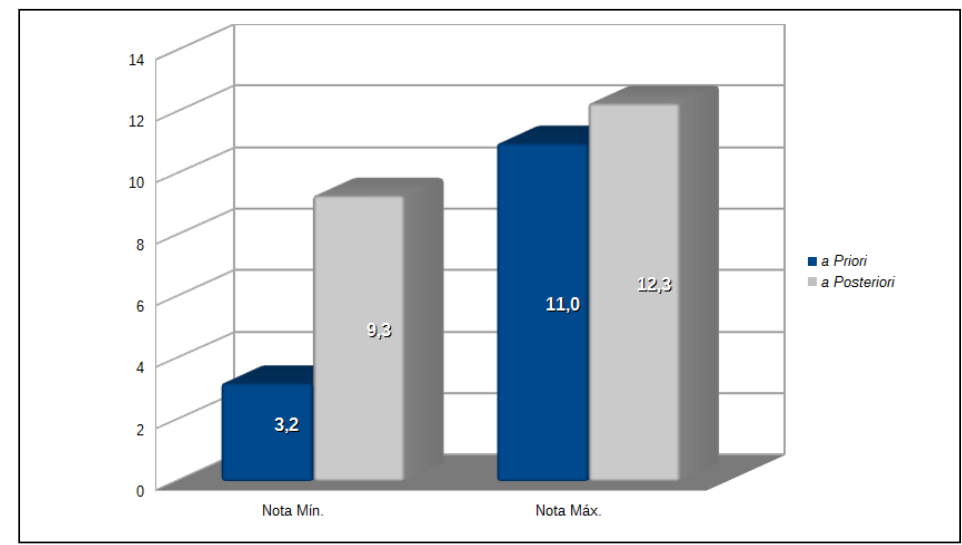

Figura 29: Gráfico Análise Comparativa das Avaliações Diagnósticas

Observando os dados obtidos, foi possível concluir que o estudante com o pior rendimento detectado na avaliação a priori teve uma evolução de, no mínimo, 6,1 pontos. Enquanto, na pior das hipóteses, o estudante com melhor aproveitamento na avaliação $a$ priori teve uma diminuição de 1,7 pontos. Observa-se que trata-se de uma situação limítrofe, dentro de uma margem relativamente satisfatória. Além disso, a pior nota obtida na avaliação a posteriori se aproximou da melhor nota obtida na avaliação a priori e a melhor nota na avaliação a posteriori sobrepujou a melhor nota na avaliação $a$ priori.

Por fim, seguindo para a análise detalhada dos dados, foram analisados os rendimentos específicos, por questão, entre as duas avaliações diagnósticas de modo comparativo, como pode ser visto na Figura 30.

Analisando os resultados obtidos, foi possível verificar que houve avanço na média de acertos em todas as questões analisadas, sendo o maior avanço na segunda questão, a qual abordava o exercício da abstração matemática e transição da representação algébrica para a representação geométrica dos entes matemáticos. O que, segundo os dados obtidos na terceira questão da avaliação diagnóstica a priori, representava a maior dificuldade dos estudantes.

Concluindo a discussão, com base nos resultados objetivos da pesquisa é possível afirmar que o software de matemática dinâmica GeoGebra constitui ferramenta auxiliadora eficaz na compreensão das especificidades matemáticas relativas ao conceito de Cálculo Diferencial e Integral aplicada para o cálculo de área e volume dos sólidos de revolução, na turma trabalhada.

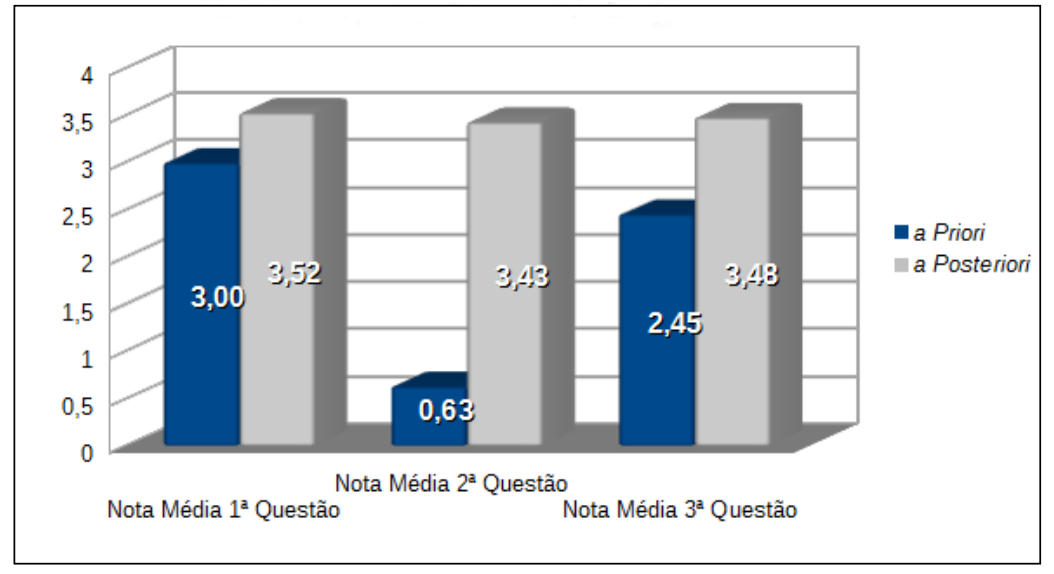

Figura 30: Gráfico Nota Média por Questão das Avaliações Diagnósticas 


\section{Considerações finais}

Fundamentada nas concepções da Engenharia Didática, a presente pesquisa, de caráter quantitativo e qualitativo, objetivou proporcionar, através de intervenção direta, uma atmosfera colaborativa de uso do software GeoGebra para o estudo de sólidos de revolução, usando o cálculo diferencial e integral, de modo que os estudantes pertencentes ao grupo estudado tiveram participação ativa, durante as atividades, no processo de formulação de conjecturas e validação matemática das hipóteses estabelecidas.

No curso dos trabalhos, ainda na etapa das análises preliminares, já era possível perceber que uma das maiores dificuldades dos estudantes era conseguir a partir da forma algébrica de uma função dada e um eixo de rotação, ao menos vislumbrar a forma geométrica que seria gerada através da revolução da função em torno do referido eixo. Entretanto, após o uso do software de matemática dinâmica GeoGebra, os estudantes apresentaram significativa melhora nesse quesito. No questionário de satisfação, quando perguntados se o software era capaz de facilitar a compreensão das especificidades matemáticas presentes nos sólidos e superfícies de revolução, relataram que a ferramenta contribuiu positivamente para a visualização e compreensão, conforme relatos:

"sim pois esclareceu muitos equívocos que tinha a respeito da diferença entre solido de revolução e superfície de revolução."

"Sim. Pois através da visualização tridimensional das figuras ficou mais fácil a compreensão do conteúdo."

E a medida que transcorreram as atividades, ficou ainda mais evidenciada a eficácia do software GeoGebra como mecanismo de ensino-aprendizagem de área e volume de sólidos de revolução no contexto abrangido pela pesquisa. No entanto, cabe ressaltar que seu uso se deu de forma coerente, no sentido de que foi conciliado à técnicas pedagógicas que exploraram suas potencialidades e limitações e aos conceitos inerentes à matemática formal, conforme orientações de Giraldo et. al. (2013)[12] e Pereira et. al. (2017) [18].

Outro fato identificado com a pesquisa que merece ser aqui considerado é que a forma tutorial com que foram constituídas as atividades e o método de desenvolvimento cronologicamente sistematizado das etapas do trabalho, tal como sua prévia divulgação ao grupo estudado, tiveram destaque como experiências positivamente avaliadas pelos estudantes, sugerindo que o uso da Engenharia Didática como metodologia de pesquisa é uma forma pedagógica agradável e interessante de planejamento e desempenho das atividades. Abaixo seguem relatos dos estudantes:

"A sequência didática ocorreu de forma linear, iniciando-se pela familiarização da ferramenta até as noções de cálculo."

"Boa, o passo a passo da sequência possibilitou melhor visualização do conteúdo abordado."

"Foi notório um planejamento bem elaborado da sequência apresentada, pois as atividades foram discutidas no início da intervenção e concluídas conforme combinado."

Sendo assim, além do que foi apresentado cabe salientar que o rol de experiências trazidas na presente pesquisa confere à formação dos pesquisadores e leitores deste trabalho interessante contribuição, ainda que de forma restrita, para discussões sobre a prática docente no ensino dos sólidos de revolução e seus desdobramentos.

\section{Referências}

[1] ALMOULOUD, S. A.; COUTINHO, C. D. Q. E. S. Engenharia Didática: características e seus usos em trabalhos apresentados no GT-19/ANPEd. REVEMAT: Revista Eletrônica de Educação Matemática, Florianópolis, SC, v. 3, p. 62-77, 2008.

[2] ALMOULOUD, Saddo Ag. Fundamentos da Didática da Matemática. Editora UFPR, 2007.

[3] ALVES, F.R.V., DE LIMA, M. V. M. Revista de Produção Discente em Educação Matemática. São Paulo, v.5 n1/2 pp.77-96. 2016.

[4] ALVES, F.R.V. Didática da Matemática. Instituto Federal de Educação, Ciência e Tecnologia do Ceará - IFCE, Universidade Aberta do Brasil - UAB, 2011. 198 p. 
[6] BOYER, Carl B.; Historia da Matemática; revista por Uta C. Merz- bach; tradução Elza F. Gomide - 2ª ed. - São Paulo: Edgard Blucher, 1996.

[7] BROUSSEAU, Guy. Theory of didactical situations in mathematics: Didactique des mathématiques, 1970-1990. Springer Science Business Media, 2006.

[8] D'AMORE, Bruno. Elementos de didática da matemática. Editora Livraria da Fisica, 2007.

[9] DANTAS, Sérgio; FERREIRA, Guilherme. Capítulo 18 Superfícies de revolução e curvas de nível. 2015. Disponível em: <http://ogeogebra.com.br/arquivos/18_superficies_curvas.pdf>. Acesso em: 18 abr. 2016.

[10] DANTAS, Sérgio Carrazedo; MATHIAS, Carmen Vieira. Formas de revolução e cálculo de volume. Ciência e Natura, v. 39, n. 1, p. 142, 2017.

[11] DOLCE, Osvaldo; POMPEO, José Nicolau. Fundamentos de Matemática Elementar 10: Geometria Espacial, Posição e Métrica. 5.ed. São Paulo. Atual, 2001. 440 p.

[12] GIRALDO, V.; CAETANO, P.; MATTOS, F. Recursos Computacionais no Ensino de Matemática. 1. ed. Rio de Janeiro: SBM, 2012.

[13] JARDIM, Deborah Farago; SILVA, Jaqueline Maria da.; PEREIRA, Marcela Martins; SOARES JUNIOR, Eduardo Antonio; NEPOMUCENA, Thamara Vieira; PINHEIRO, Thais Rodrigues. Estudando Limites com o Geogebra Revista Vozes dos Vales. N. 08, Ano IV, 2015.

[14] MACHADO, Glaucio José Couri.Educação e ciberespaço: estudos, propostas e desafios. Aracajú: Virtus, 2010.

[15] MORAN, José Manuel. Os novos espaços de atuação do professor com as tecnologias. Revista Diálogo Educacional, Curitiba, v. 4, n. 12, p.13-21, Mai/Ago 2004. Quadrimestral.

[16] PAIS, Luiz Carlos. Didática da Matemática: uma análise da influência francesa. Autêntica, 2015. 128p.

[17] PEREIRA, Lucas Rodrigues. Práticas de Ensino em Geometria Plana. 2017. 171 f. Dissertação (Mestrado) Curso de Profmat, Universidade Federal do Jequitinhonha e Mucuri, Teófilo Otoni, 2017.

[18] PEREIRA, Lucas Rodrigues; DA SILVA, Jaqueline Maria; JARDIM, Deborah Faragó. Practices for Geometry Teaching Using GeoGebra. In: Conference Proceedings. New Perspectives in Science Education. libreriauniversitaria. it Edizioni, 2017. p. 211.

[19] ROSA, Rosemar. Trabalho docente: Dificuldades apontadas pelo professores no uso das tecnologias. Revista Encontro de Pesquisa em Educação, Uberaba, p.214-227, 21 out. 2013. Anual. Disponível em: <http://revistas.uniube.br/index.php/anais/article /viewFile/710/1007>. Acesso em: 12 maio 2016.

[20] SANTAELLA, Lucia. Da cultura das mídias à cibercultura: o advento do pós-humano. $22^{\mathrm{a}}$ ed. Porto Alegre: Revistas FAMECOS, 2003.

[21] SILVA, Jaqueline Maria da; SOUZA, Fabio Silva; CARIUS, Ana Carolina; JARDIM, Deborah Farago. Mathematical Modeling and the Differential and Integral Calculus Teaching Challenges. ICMTA - 17. Modelling perspectives: looking in and across boundaries. Conference Contributions. Notthingham. 2015.

[22] STEWART, James. Cálculo. Vol I. 5ª .ed. São Paulo: Pioneira Thompson Learning, 2006. 578 p. 